\title{
BENEFIT INCIDENCE OF PUBLIC TRANSFERS: EVIDENCE FROM THE PEOPLE'S REPUBLIC OF CHINA
}

Ke Shen and Sang-Hyop Lee

\section{No.413 ADB ECONOMICS


ADB Economics Working Paper Series

Benefit Incidence of Public Transfers:

Evidence from the People's Republic of China

Ke Shen and Sang-Hyop Lee

No. 413 | 2014
Ke Shen (shenke@fudan.edu.cn) is an Assistant Professor at the Demographic Research Institute of Fudan University. Sang-Hyop Lee (leesang@hawaii.edu) is a Professor of Economics and Director of the Center for Korean Studies at the University of Hawaii at Manoa, and an Adjunct Senior Fellow at the East-West Center. 
Asian Development Bank

6 ADB Avenue, Mandaluyong City

1550 Metro Manila, Philippines

www.adb.org

(C) 2014 by Asian Development Bank

November 2014

ISSN 2313-6537 (Print), 2313-6545 (e-ISSN)

Publication Stock No. WPS146906-3

The views expressed in this paper are those of the author and do not necessarily reflect the views and policies of the Asian Development Bank (ADB) or its Board of Governors or the governments they represent.

ADB does not guarantee the accuracy of the data included in this publication and accepts no responsibility for any consequence of their use.

By making any designation of or reference to a particular territory or geographic area, or by using the term "country" in this document, $A D B$ does not intend to make any judgments as to the legal or other status of any territory or area.

Notes:

In this publication, "\$" refers to US dollars.

The ADB Economics Working Paper Series is a forum for stimulating discussion and eliciting feedback on ongoing and recently completed research and policy studies undertaken by the Asian Development Bank (ADB) staff, consultants, or resource persons. The series deals with key economic and development problems, particularly those facing the Asia and Pacific region; as well as conceptual, analytical, or methodological issues relating to project/program economic analysis, and statistical data and measurement. The series aims to enhance the knowledge on Asia's development and policy challenges; strengthen analytical rigor and quality of ADB's country partnership strategies, and its subregional and country operations; and improve the quality and availability of statistical data and development indicators for monitoring development effectiveness.

The ADB Economics Working Paper Series is a quick-disseminating, informal publication whose titles could subsequently be revised for publication as articles in professional journals or chapters in books. The series is maintained by the Economics and Research Department. 


\section{CONTENTS}

FIGURES $\quad$ iv

ABSTRACT $\quad v$

$\begin{array}{lll}\text { I. INTRODUCTION } & 1\end{array}$

II. METHODOLOGY 2

III. BENEFIT INCIDENCE OF PUBLIC SPENDING BY RESIDENCE 3

A. Education 3

B. Health Care $\quad 5$

$\begin{array}{ll}\text { C. Pensions } & 7\end{array}$

IV. BENEFIT INCIDENCE OF PUBLIC SPENDING BY GENDER

A. Education 9

B. Health Care 11

C. Pensions 12

V. BENEFIT INCIDENCE OF PUBLIC SPENDING BY PER CAPITA HOUSEHOLD INCOME

A. Education 13

B. Health Care $\quad 15$

$\begin{array}{ll}\text { C. Pensions } & 17\end{array}$

VI. BENEFIT INCIDENCE OF TOTAL PUBLIC TRANSFERS 19

A. Residence 19

B. Gender 20

C. Income Quartiles $\quad 22$

D. Incidence of Total Public Transfers 23

$\begin{array}{lll}\text { VII. CONCLUSION } & 23\end{array}$

$\begin{array}{ll}\text { APPENDIX } & 27\end{array}$

$\begin{array}{lr}\text { REFERENCES } & 29\end{array}$ 


\section{FIGURES}

$1 \quad$ Per Capita Public Education Spending by Residence 4

$2 \quad$ Aggregate Public Education Spending by Residence

3 Per Capita Public Health-Care Spending by Residence 6

$4 \quad$ Aggregate Public Health-Care Spending by Residence $\quad 7$

5 Per Capita Public Pension Spending by Residence 8

6 Aggregate Public Pension Spending by Residence 9

$7 \quad$ Per Capita Public Education Spending by Gender 10

$8 \quad$ Aggregate Public Education Spending by Gender 10

$9 \quad$ Per Capita Public Health-Care Spending by Gender 11

10 Aggregate Public Health-Care Spending by Gender 12

11 Per Capita Public Pension Spending by Gender 12

12 Aggregate Public Pension Spending by Gender 13

13 Per Capita Public Education Spending by Income Quartile 14

14 Distribution of Aggregate Public Education Consumption by Income Quartile 15

15 Aggregate Public Education Spending by Income Quartile 15

16 Per Capita Public Health-Care Consumption by Income Quartile 16

17 Distribution of Aggregate Public Health-Care Spending by Income Quartile 17

18 Aggregate Public Health-Care Consumption by Income Quartile 17

19 Per Capita Public Pension Spending by Income Quartile 18

20 Distribution of Aggregate Public Pension Spending by Income Quartile 18

$21 \quad$ Aggregate Public Pension Spending by Income Quartile 19

22 Per Capita Total Public Transfers by Residence 19

23 Aggregate Public Transfers to Different Age Groups by Residence 20

$24 \quad$ Per Capita Total Public Transfers by Gender 21

25 Aggregate Public Transfers on Different Age Groups by Gender 21

26 Per Capita Total Public Transfers by Income Quartile 22

27 Aggregate Public Transfers on Different Age Groups by Income Quartile 22

28 Per Capita Total Public Transfers 23 


\begin{abstract}
Benefit incidence analyses provide important insights into problems facing any government struggling to deliver essential and equitable social services. Utilizing the framework of the National Transfer Accounts Project, this paper analyzes the benefit incidence of public transfers across generations and socioeconomic groups in the People's Republic of China in 2009. Public education transfers were equally distributed by residence, gender, and income groups at the primary and secondary levels but favored city dwellers, females, and the wealthy at the tertiary level. Public health-care programs tended to equally target the young and middle-aged from different socioeconomic groups but tilted toward urban dwellers, males, and higher income groups at older ages. Public pension spending strongly favored high-income groups, with rural residents, females, and lower income groups receiving greatly reduced benefits. Our results also indicate that total public spending favored elderly people as spending per person 65 years and older was twice that per child younger than 19. In the next 10 or 20 years, the government should endeavor to improve and strengthen public support systems. In addition to this effort, the currently fragmented health insurance system and pension system should move toward a unified system to reduce inequalities in benefit incidence across socioeconomic groups.
\end{abstract}

Keywords: benefit incidence, public transfers, the People's Republic of China JEL Classification: E62, H53, O15 


\section{INTRODUCTION}

Three decades of virtually uninterrupted hyper economic growth have propelled the People's Republic of China (PRC) into the ranks of middle-income countries. However, this rapid economic growth has been accompanied by an equally rapid increase in levels of inequality. The official Gini coefficient reached 0.47 in 2012 (Xinhua News 2013) which is greater than the international alert line of 0.4 set by the United Nations (UN-HABITAT 2008). In response to the great concerns about inequality, the government has been paying close attention to redistributive goals through a wide variety of instruments. Public transfers targeting vulnerable groups to promote equality and improve the welfare of the population serve as one of these instruments. In the past decade, the government has made great strides in instituting and improving public sector programs to provide public education, health care, and pensions for its citizens. For example, in 2005, textbook and miscellaneous fees were waived for one-third of students enrolled in compulsory education in western and central rural areas of the country, reaching all students in primary and junior high school by 2008. In addition to broader coverage, it is essential to know whether disadvantaged groups, such as rural dwellers, females, or the poor, benefit more from public transfers in order to justify them as a rationale for public spending.

A second distinctive feature of public transfers is to reallocate resources from the working-age population to both children and the elderly in terms of education, health care, and pensions (Lee 2003). This suggests that public transfers are unevenly distributed across generations. Downward transfers, such as education, from older to younger cohorts might crowd out upward transfers, such as pensions and health care; however, less attention has been paid to this area. One notable study by Bommier et al. (2010) shows that all generations born from 1950 to 2050 in the United States (US) are net gainers in combined public transfers net of taxes, while many of today's older people are net losers. With the accelerated aging occurring in the PRC, the old-age dependency ratio will increase rapidly in the coming years, thus the lack of balance in benefits across generations will become even more pronounced. For example, pension reform is hotly debated in the PRC just as it is in industrialized nations. The necessity to reform social security is undisputed, but there is strong disagreement about how that reform should be designed. The dilemma is that either future generations are unfairly saddled with the burden of a large public debt or current generations are unfairly treated, especially those nearing retirement age (Bommier et al. 2010).

Measuring how government spending is distributed is a matter of long-standing concern in economics literature (Meerman 1979, Selowsky 1979, and van de Walle and Nead 1995). A more recent study in Latin American countries (Turra, Holz, and Cotlear 2011) showed that the distribution of public transfers across income groups and the distribution of these transfers across generations are not independent; instead, they are closely related to each other. They found that much of the regressive nature of public expenditures across income groups in Brazil and Chile was due to generational allocations as public spending was almost neutral in education, lightly progressive in health care, and strongly regressive in public pensions. Following the framework of Turra, Holz, and Cotlear (2011), we extended our analyses to look into the distribution of public spending by residence, by gender, and by income, and to figure out its link with distributions across generations in the PRC. Section II introduces the methods used to estimate the benefit incidence of public transfers. Section III describes the age patterns of public spending by sector and by residence. Section IV presents the age patterns of public spending by sector and by gender. Section $\vee$ shows the age distributions of public spending by sector and by income. Section VI shows the age distributions of combined public spending by socioeconomic groups, and Section VII concludes. 


\section{METHODOLOGY}

To understand and appreciate the benefit incidence of public spending, we used the method of the National Transfer Accounts (NTA) Project. NTA captures a fundamental feature of all societies: the economic life cycle. The life-cycle deficit generated by the mismatch between consumption and labor income across age groups should be financed through intergenerational transfers, asset income, or dissaving. Essentially, the national transfer flow account is based on the following identity:

$$
C(x)-Y^{l}(x)=\tau^{+}(x)-\tau^{-}(x)+Y^{A}(x)-S(x)
$$

The left-hand side represents life-cycle deficit at age $x$, the difference between consumption $C(x)$ and labor income $Y^{l}(x)$. The right-hand side is the age reallocation system that consists of two economic mechanisms: net transfers $\tau^{+}(x)-\tau^{-}(x)$, and asset-based reallocations equal to asset income $Y^{A}(x)$ net of savings $S(x)$. Except for labor income, the other components can be distinguished by public or private sector. This paper focuses on public transfers through which the government tries to fill the gap between consumption and labor income across generations. Public transfers are comprised of two components: in-kind transfers, such as public education and public health-care consumption; and cash transfers, such as public pensions.

Using the framework of the NTA, the analyses are based on micro-level household data from the 2010 wave of China Family Panel Studies (CFPS), which collected data on consumption, income, and other information in the past year (2009), and macro-level data from the System of National Accounts and government administrative records. The CFPS is a nationally representative household survey that has been collected every year since 2010. The 2010 survey covered 25 out of 31 provinces and targeted about 16,000 households, including adults and children under the age of 16 . The CFPS provides detailed information on household structure, income, and expenditures, which facilitated our estimates. CFPS data collection is under strict quality control (Yan et al. 2012). A comparison of income data between the 2010 wave of CFPS and the 2010 wave of the China General Social Survey showed that the income distributions were quite similar (Xu et al. 2012).

The first step was to estimate age profiles of public expenditures on education, health care, and pensions. To estimate the age profile of public education consumption, administrative data from the Educational Finance Statistical Yearbook 2010 were used to input the cost per student enrolled by level of education, and CFPS data were used to estimate the age-specific enrollment rates in each level of education (Chen 2010). The age profile of public pension expenditures was based on survey responses on pension benefits received in 2009. However, CFPS provides pension benefits on a household basis only; therefore, pension benefits were assumed to be equally distributed among the elderly living in the household.

The age profile of public health-care consumption is more complex. The macro control for public health consumption in NTA is comprised of two parts: medical expenditures reimbursed by public health insurance and government health-care spending. The age-specific, reimbursed health consumption originates directly from the responses on the CFPS survey. However, the CFPS has no information on inpatient and outpatient utilization rates, which is essential to estimate the age profile

\footnotetext{
The elderly in urban areas are defined as women above the age of 55 and men above the age of 60 as those are the normal retirement ages in urban areas. In rural areas, the elderly are defined as people above the age of 60 as they are entitled to pension benefits. If there are no elderly individuals in the household and household pension benefits are positive, the amounts are allocated to the oldest individual living in the household.
} 
of government health-care spending as was done in Brazil and Chile (Turra, Holz, and Cotlear 2011). Instead, we calculated out-of-pocket medical expenditures based on CFPS data as a substitute for utilization rates, with the assumption that medical expenditures are proportional to utilization rates. Finally, we combined the age profile of reimbursed health consumption and the age profile of out-ofpocket medical expenditures to formulate the age profile of public health consumption.

The second step was to estimate age profiles of public transfers across socioeconomic groups. We split the CFPS household data into urban and rural residence, gender, and income quartiles, and estimated the above-mentioned age profiles using each subsample. Subsequently, most age profiles were smoothed except for education ${ }^{2}$ as age patterns of public education spending have too many discontinuities that are not random but are the product of specific ages of entering and leaving school (UN 2013).

The last step was to adjust the smoothed and non-smoothed profiles to macro controls. As the NTA method imputes only macro controls for pubic transfers by purpose for the whole nation, we further needed to calculate corresponding macro controls for each sub-sample. Taking public education spending as an example, we used the ratio of average value of spending per capita in urban areas to the value in rural areas to divide the macro control for public education spending. These macro controls were then used to scale the NTA age profiles so that the NTA aggregate estimates matched the estimates from the System of National Accounts.

\section{BENEFIT INCIDENCE OF PUBLIC SPENDING BY RESIDENCE}

In this section, we investigate the urban-rural differentials in the age distribution of public expenditures in three categories: public education, health care, and pensions. The analysis is based on a comparison of per capita values and aggregate values across ages between urban and rural areas.

\section{A. Education}

Education has long attracted government subsidies in the PRC because of the equity considerations and high externalities involved. The government is the main provider of education with over $90 \%$ of students in primary and secondary education attending public schools. Government spending per student normally increases with the level of education. According to the Educational Finance Statistical Yearbook 2010, the outlays for college education are nearly 3 times the amount spent on primary schools (Chen 2010).

As shown in Figure 1, most public education spending targeted students under the age of 25 while some also reached urban adults in their 30 s who were receiving post-graduate education or adult education. Public education expenditure for the age group 6-16 was equal in urban and rural areas due to the government's endeavor to promote the balanced development of compulsory education. The government has mandated public funding for 9 years of compulsory education since 2001, and as mentioned previously, by 2005, textbook and miscellaneous fees were waived for about one-third of students in western and central rural areas. This program was extended to all rural students in primary and junior high school by 2007 and further covered all urban students by 2008. Compulsory education

2 We used locally weighted scatterplot smoothing (LOWESS) with a bandwidth of 0.1. The default bandwidth in a LOWESS command is 0.8 . The smaller the number of the bandwidth, the less smoothing. 
is now virtually universal. In 2009 , the crude enrollment rate in primary school was over $100 \%$ and in junior high school was about $99 \%$ (Chen 2010).

Two distinctions between the urban and rural populations also emerge in Figure 1. First, public spending on pre-primary education was less in rural areas due to lower enrollment rates in kindergartens. In recent years, many local governments have been expanding rural kindergartens, but the urban-rural gap cannot be fully eliminated in the short term. Second, public spending on college education was much greater for the urban population. Per capita education spending at age 20 reached 3,890 yuan (CNY) in urban areas, while the figure in rural areas was only CNY2,380, about $40 \%$ less. The PRC has seen the fastest expansion in higher education in its history. According to The People's Republic of China Yearbook 2011, in 10 years since 2000, annual enrollment in college education tripled from 2.2 million to 6.6 million. This expansion has been more beneficial for urban youths. The 2010 census revealed that of the population aged $20-29$, only $20 \%$ had college or higher education in the nation as a whole, but nearly $40 \%$ of those aged $20-24$ and $32 \%$ of those aged $25-29$ in urban areas were college educated. In addition, the share of rural students in the top universities has shown an evident downward trend in recent years. ${ }^{3}$ On one hand, low enrollment rates in the countryside are indicators of poor performance as college enrollment is generally determined by how students do on national examinations. On the other hand, low enrollment also reflects income constraints faced by poor rural households as tuition fees rise.

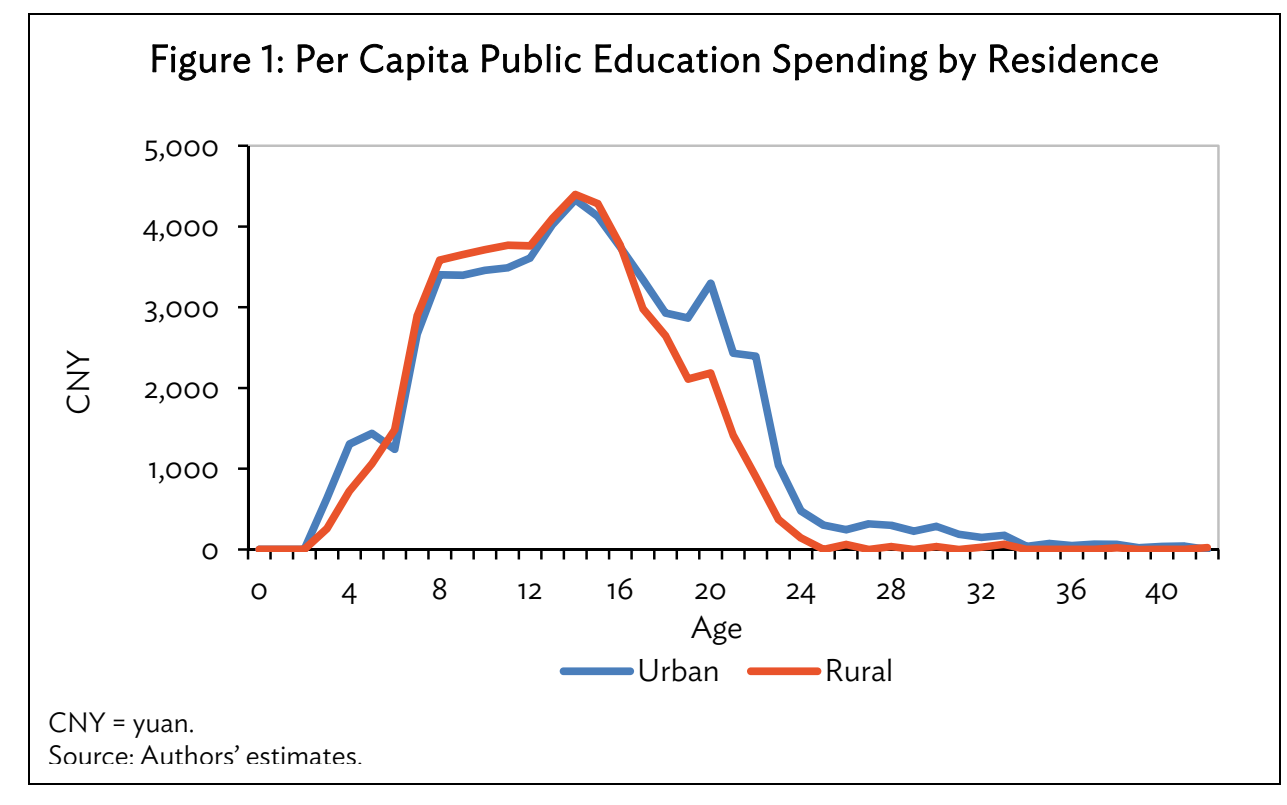

Figure 2 presents age distributions of aggregate public education expenditure. Aggregate public spending on education in urban areas was $16 \%$ higher than that in rural areas. Unlike per capita values, more aggregate public funding was allocated to rural children under the age of 16 because of the larger population size. With the 3-decade long enforcement of family planning policies, urban couples strictly follow the one child per couple rule, while rural couples in a majority of provinces are allowed to have a second child if the first is a female. Hence, the number of children in rural areas is larger than that in urban areas. In contrast, public education funding for urban youth older than 17 years was much greater than that for rural people. In addition to higher per capita values, the greater

3 People's Daily. 2009. Let's Talk: Focus on Fewer and Fewer Rural Students in Universities (in Chinese). 15 January. http://edu.people.com.cn/GB/1053/8676707.html 
number of young people in cities due to frequent and massive rural-to-urban migration also accounts for the differences in aggregate values.

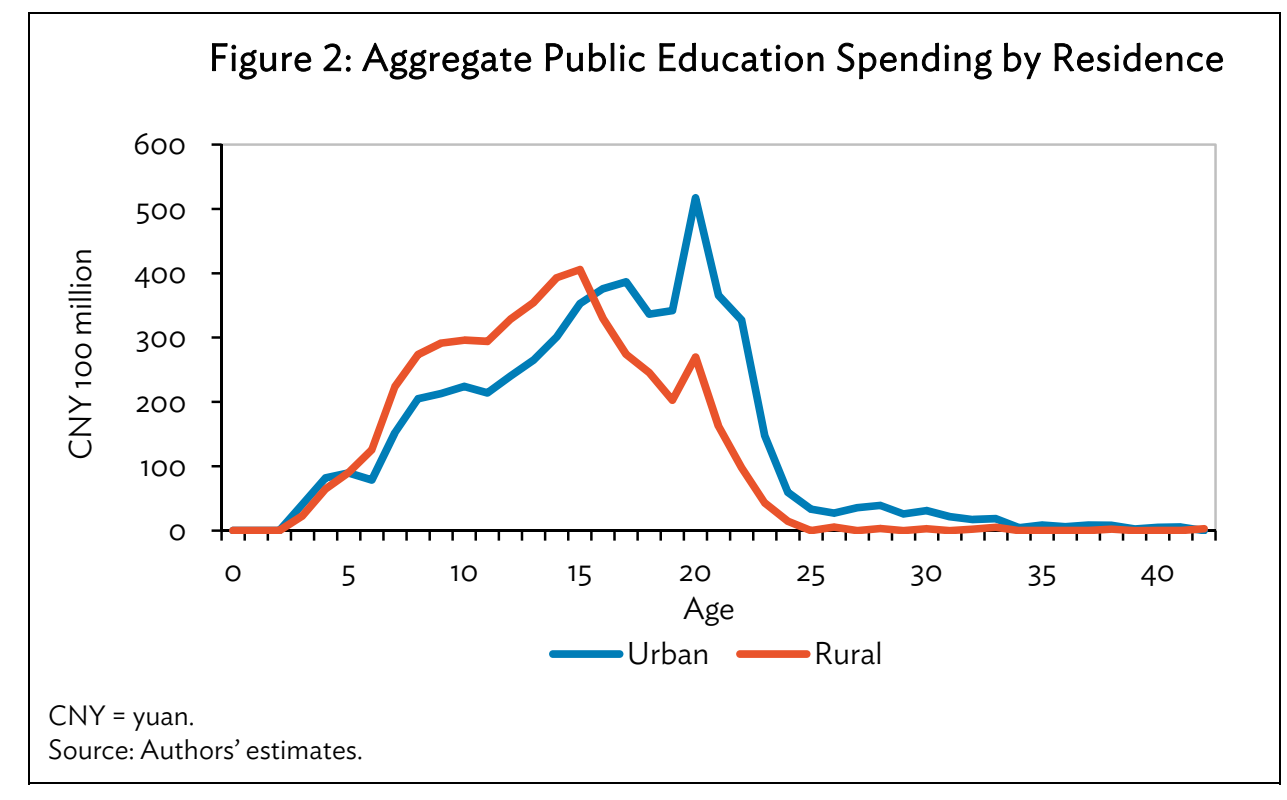

\section{B. Health Care}

Public health-care institutions dominate the PRC's health-care system. In 2009, person-time patients treated by public institutions amounted to 1.8 billion in contrast to only 153 million in private institutions, as indicated in the Public Health Statistical Yearbook 2012. The number of patients hospitalized in public facilities was 78 million while the number in private organizations was only 6.8 million.

As shown in Figure 3, the age profile of per capita public health-care spending has a J-shape in both urban and rural areas, i.e., per capita spending is high in infancy, then decreases in the teenage years, and increases again at middle age. The peak of public health spending occurs around age 80 in urban and rural areas, while the peak value in urban areas is almost twice that of rural areas. Urban dwellers benefit more from public health-care funding than rural dwellers at all ages, in particular, after the age of 60 .

One major reason for this differential is the segregated public health insurance system in the PRC. There are two major types of insurance in urban areas: employees covered by the Urban Employees Basic Medical Insurance, established in 1998; and unemployed residents under the Urban Residents Basic Medical Insurance, piloted since 2007. In rural areas, nearly $80 \%$ of residents (about 640 million) did not have any health insurance in 2003 (Ministry of Health 2004). To address this problem, the government launched the New Cooperative Medical Scheme in 2003 which dramatically expanded coverage to about $96 \%$ (836 million) of the rural population in 2010 (Sheng 2011). Benefit packages differed substantially among these three programs. For example, the average inpatient reimbursement rate for urban employees was 65\% in 2008 and $45 \%$ for urban residents in 2007, while the figure for the New Cooperative Medical Scheme was only 41\% in 2009 (Barber and Yao 2010). More generous health insurance benefits encouraged urban dwellers to make intensive use of public health services. In particular, public health-care spending on urban retirees increased sharply as the deductibles and reimbursements are more favorable for retirees than for employees. This gap between 


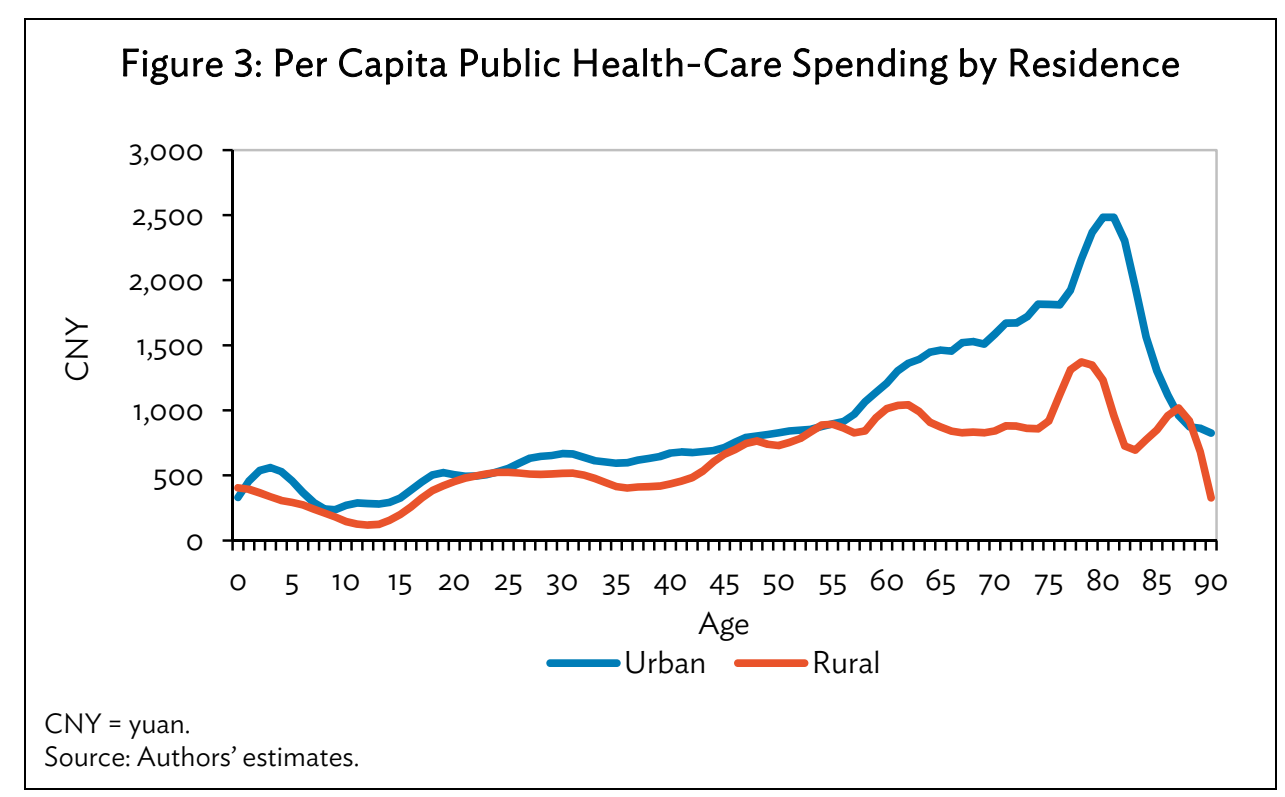

urban and rural areas in public health-care spending is expected to shrink in the coming years as the government raised its subsidy to the New Cooperative Medical Scheme from CNY40 per enrollee annually in 2006 to CNY280 in 2013.

A second reason is the concentration of health-care facilities and personnel in urban areas. According to the China Social Statistical Yearbook 2013 in 2009, the number of beds in health institutions per thousand persons in urban areas was 5.5 in contrast to 2.4 in rural areas, and there were 2.1 million health-care personnel in urban areas but only 1.3 in the countryside (Li 2013). Consequently, urban dwellers have better access to public health resources.

The age profiles in urban areas in the PRC were closer to the pattern in developed countries, while in other newly emerging countries, such as Brazil and Chile, the increase in public health-care expenditure at old ages is less evident (Turra, Holz, and Cotlear 2011).

For aggregate values, public health-care spending in urban areas was about $30 \%$ greater than that in rural areas, which was a larger gap than that in public education spending. As presented in Figure 4, the age distributions of aggregate public health-care consumption exhibited an inverted Ushape, reflecting the age composition of the population. For instance, there is a notch at around age 50 due to birth deficits during the great famine from 1959 to 1961 while the bump at age 47 reflects the baby boom generation after the famine. Rapid population aging will significantly elevate the fiscal burden of health care given the greater per capita spending at older ages. 


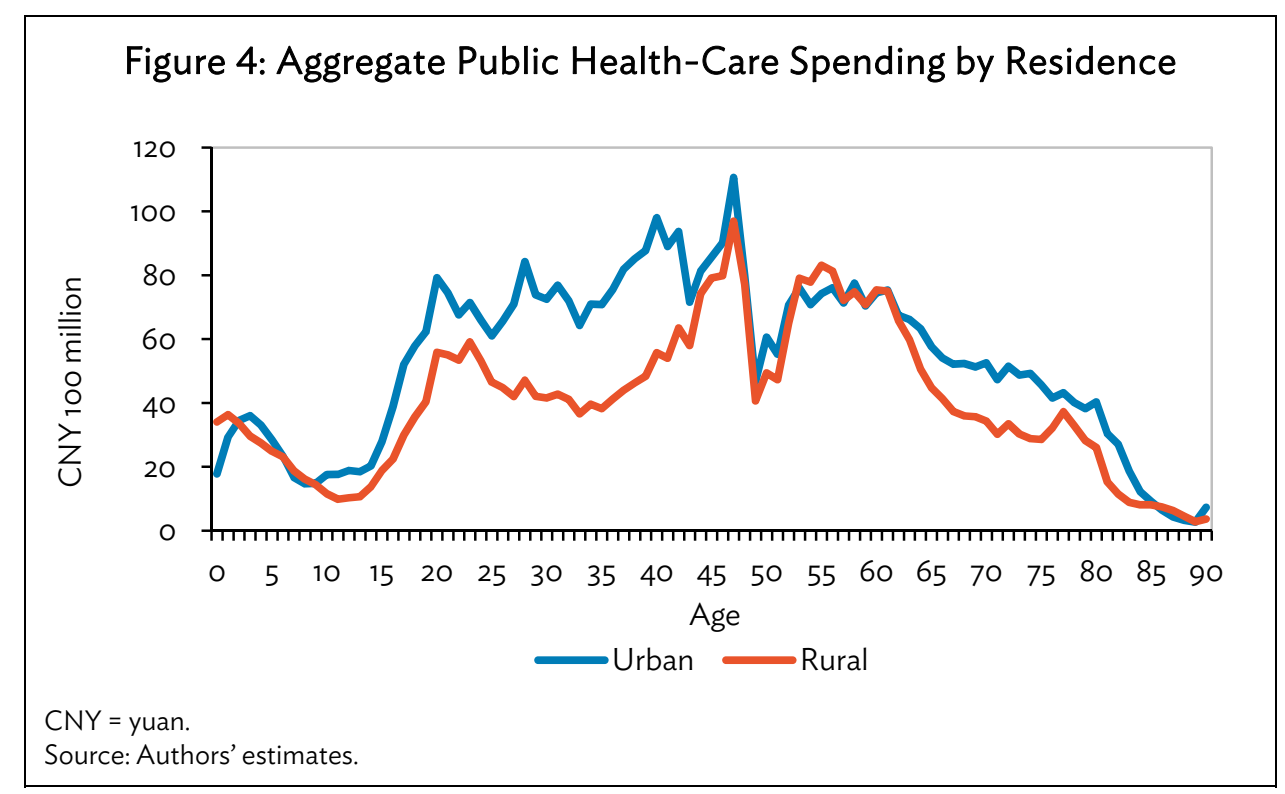

\section{Pensions}

As shown in Figure 5, there were huge differences in the age profiles of per capita pensions between urban and rural areas. Per capita annual pensions in urban areas increased quickly peaking around age 75 with a value of CNY8,300. In contrast, per capita pensions in rural areas were roughly flat at age 60 and older with a much lower value of CNY1,500. The urban-rural gap in pension benefits mainly results from the fragmentation of the emerging public old-age support system in the PRC, an arrangement that dates back to the socialist years with a social and economic system that separated the rural and urban populations, with the latter working in different types of organizations. The ones who benefited the most are government employees (including military personnel) who do not need to pay into the system but receive up to $100 \%$ of pre-retirement income (Pozen 2013). By comparison, rural people trail far behind in social security benefits, though the government has recently made great strides in expanding pension coverage for them. The new rural pension scheme was piloted in 2009 and covered roughly 72.8 million individuals, which is $10 \%$ of the rural population. Under this insurance scheme, the individual amount of contribution is currently set at up to CNY1,000 annually and the monthly payout is CNY55 (roughly \$9).

4 There is a sharp increase in urban pension benefits over age 85, which may arise from a few outliers and the small sample size at very senior ages. 


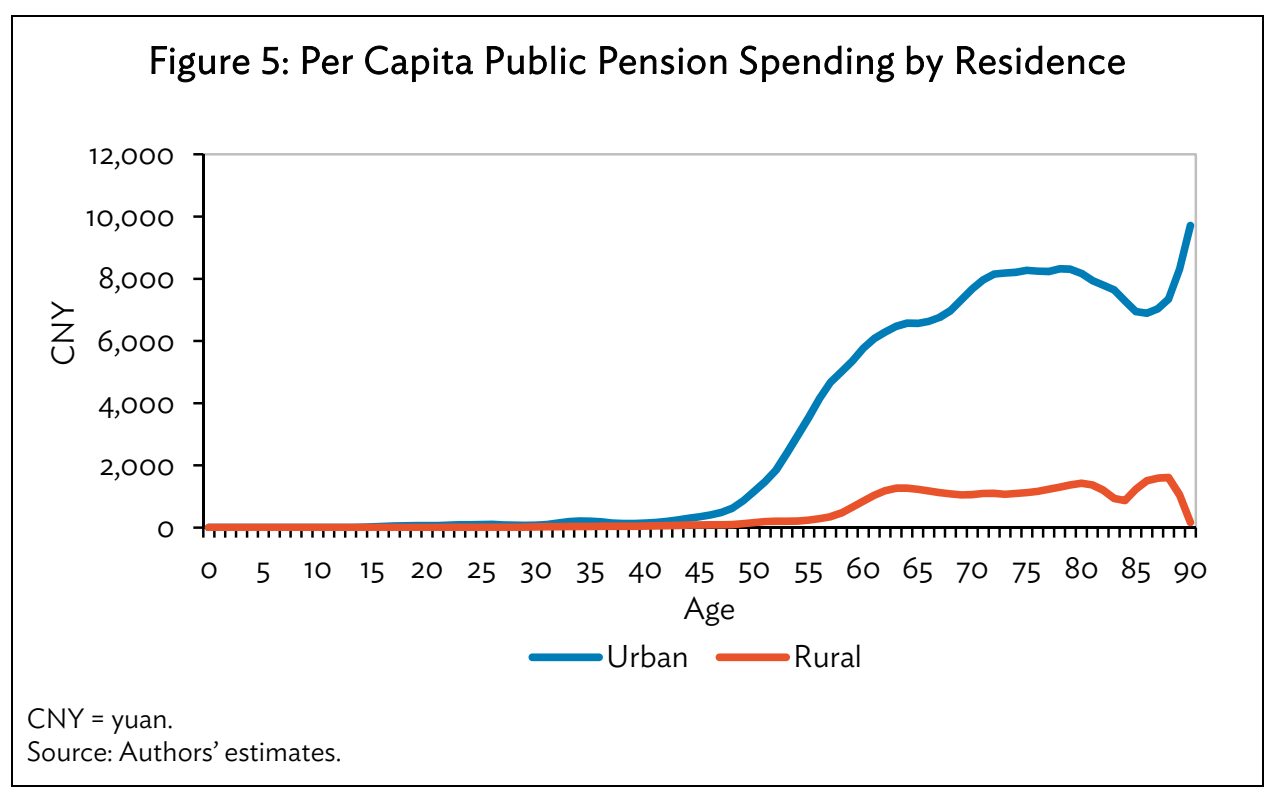

The pension systems not only differ in values of benefits per beneficiary but also in qualifying ages for pensions. For example, the retirement age is set at 50 or 55 for urban female workers and at age 60 for urban male workers, while the qualifying age for pensions is 60 years in rural areas. This explains why per capita pension payments in urban areas pick up in the early 50 s age group, while they do not start to increase in rural areas until the late 50s. The vast differences in pension systems between urban and rural dwellers also affect the models of elderly support. According to the 2010 census, up to $70 \%$ of the urban elderly relied on public pensions as their main source of income in contrast to only about $10 \%$ in the countryside. The weak pension system in rural areas increases income uncertainty at older ages, especially in the context of declining fertility and extended life expectancy, which could also lead to meager consumption.

As presented in Figure 6, both age profiles of aggregate pension spending exhibit an inverted $\mathrm{U}$-shape with the peak at around age 60. The urban-rural gap in pension benefits is more pronounced than that in public education and health-care consumption. In aggregate terms, public pension expenditure in cities is almost 5 times greater than in the countryside. The urban elderly aged 60 received CNY356 billion in pension benefits in total, in contrast to only about CNY64 billion in the countryside. This indicates that population aging and rapid urbanization will put severe strains on the government-run pension system in the coming years. 


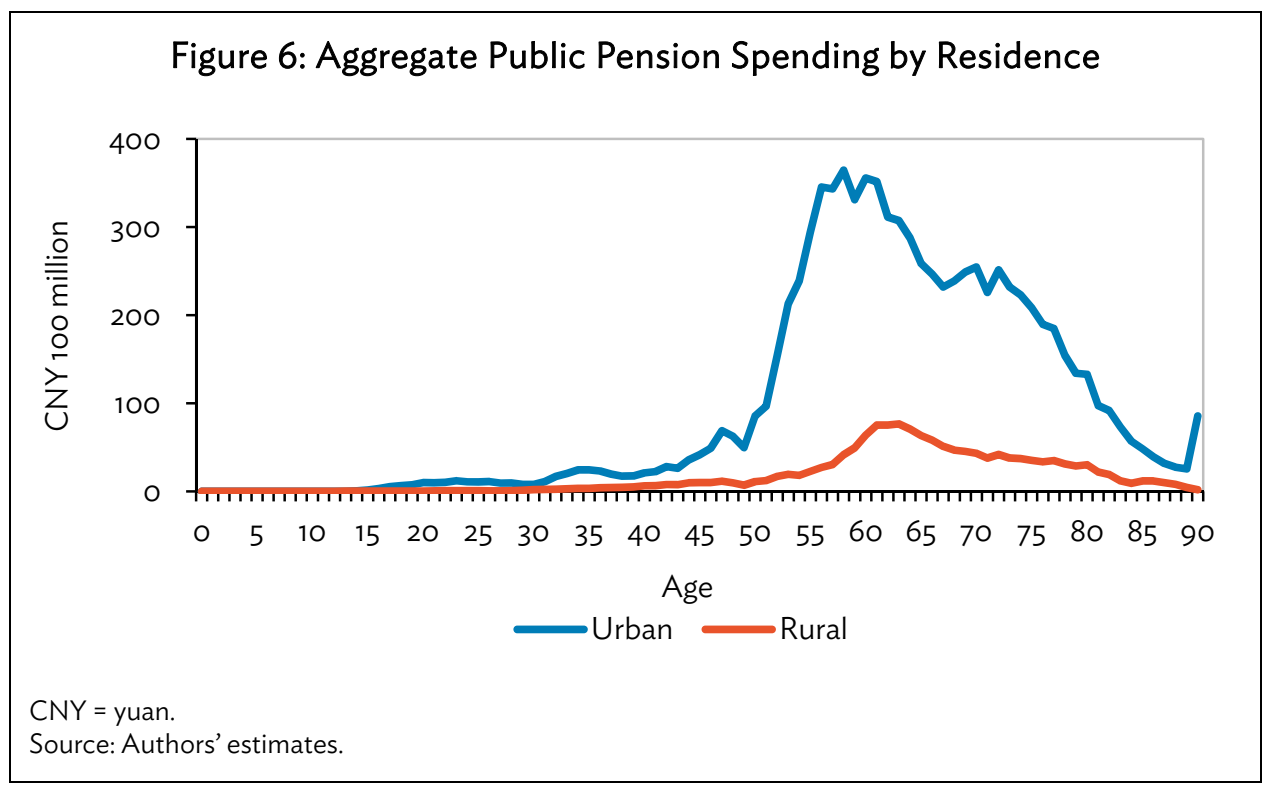

\section{BENEFIT INCIDENCE OF PUBLIC SPENDING BY GENDER}

\section{A. Education}

As indicated in Figure 7, per capita spending on public education is nearly identical for males and females younger than the age of 17 as enrollment rates in primary school and high school are almost the same. Lee (2012) indicated that the 3-decade long enforcement of the one-child policy inadvertently promoted educational gender equality in the PRC. Females aged 18-23 received even more public education transfers than their male counterparts due to higher college enrollments. In 1999, the government made a strategic decision to expand higher education in order to increase human capital and to relieve employment pressure in the urban sector. The number of new students admitted to college increased by more than 40\% in 1999, and the expansion continued in subsequent years (Li, Whalley, and Xing 2013). By 2005, annual enrollment had more than quadrupled compared with the level in 1998. Meanwhile, many studies have demonstrated a growing female dominance in school performance in recent decades in the PRC and in other countries (e.g., Lai 2010, and Buchmann and DiPrete 2006). Lai found that girls outperformed boys throughout both primary and middle schools; hence, the radical expansion in higher education has mainly benefited females. The gap in college enrollments has even reversed to favor women recently (Wu and Zhang 2010). 


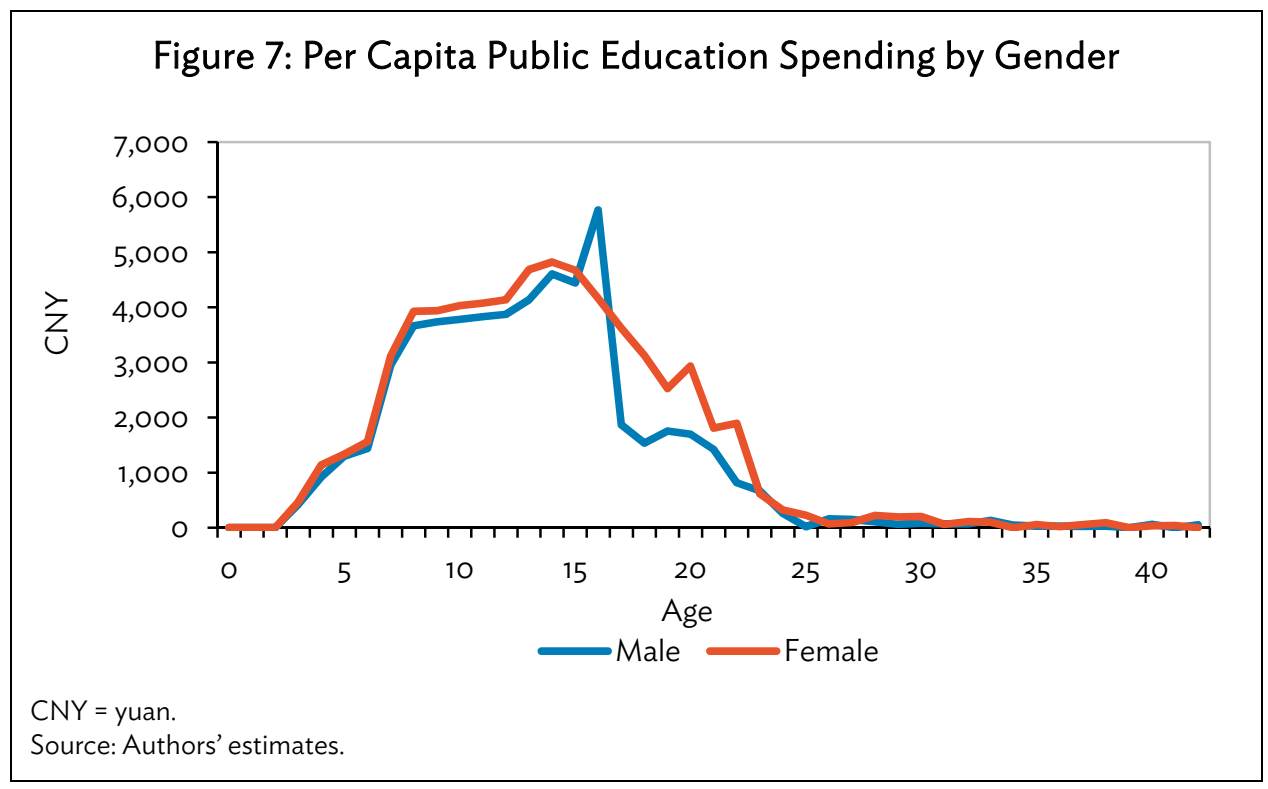

Aggregate public education expenditure was roughly balanced between males and females. As shown in Figure 8, the aggregate profiles at age 20 expand for both due to higher tuition fees for college and the larger cohort size. The total fertility rate in the PRC hit replacement level (2.1 children per couple) in 1990 and has decreased ever since. Thus, the cohort aged 20 in 2010 is larger than the younger cohorts.

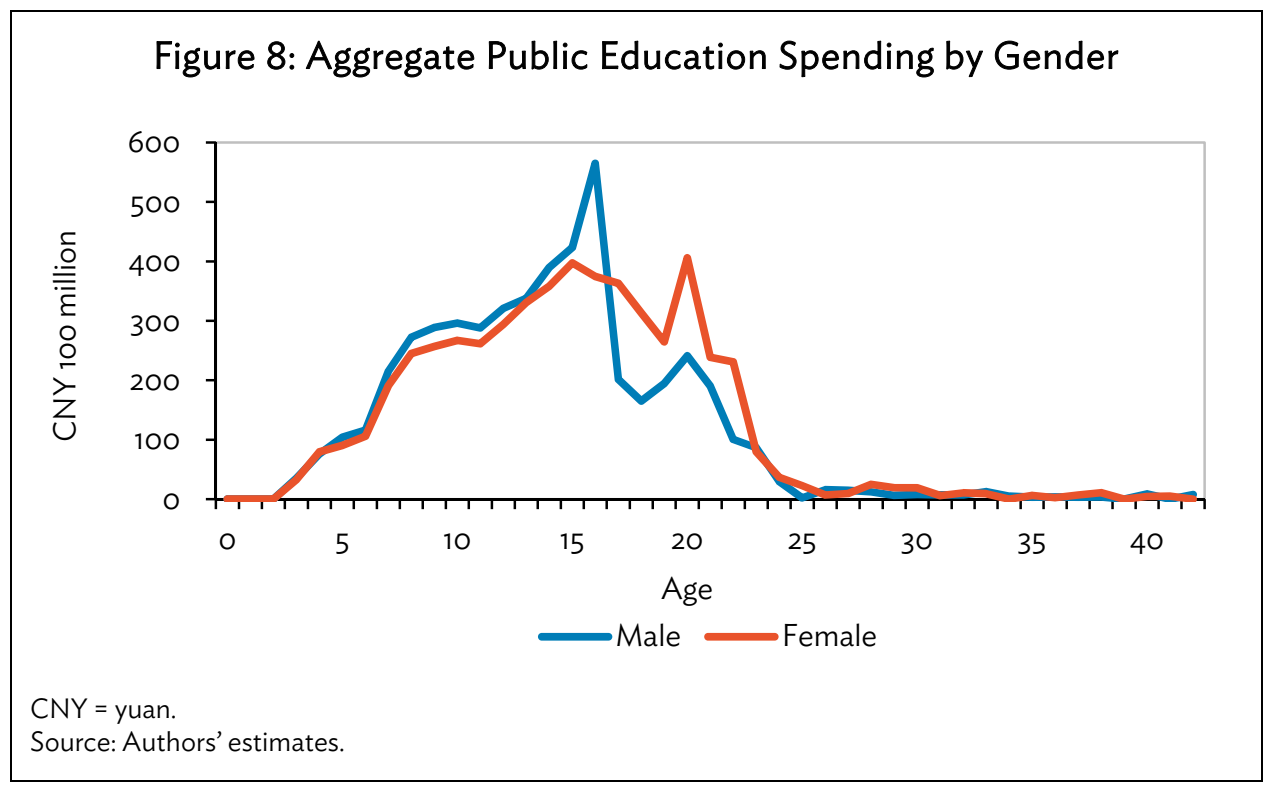




\section{B. Health Care}

As shown in Figure 9, there were no major differences in per capita public health consumption between males and females aged 10-60. At very young ages, boys received more health care than girls, which might arise from higher male infant mortality and the son preference in traditional families in the PRC. At older ages, men also consumed more public health resources than women. In general, the urban health insurance scheme is directly tied to employment status before retirement for the elderly, with coverage for other family members not provided (Strauss et al. 2012). Higher male employment rates in past decades-especially employment in government and public institutions-means that older men are more likely to be insured or to benefit from generous health insurance packages. At the peak age of 80 , per capita public health spending for women was about CNY1,764 in contrast to CNY2,238 for men.

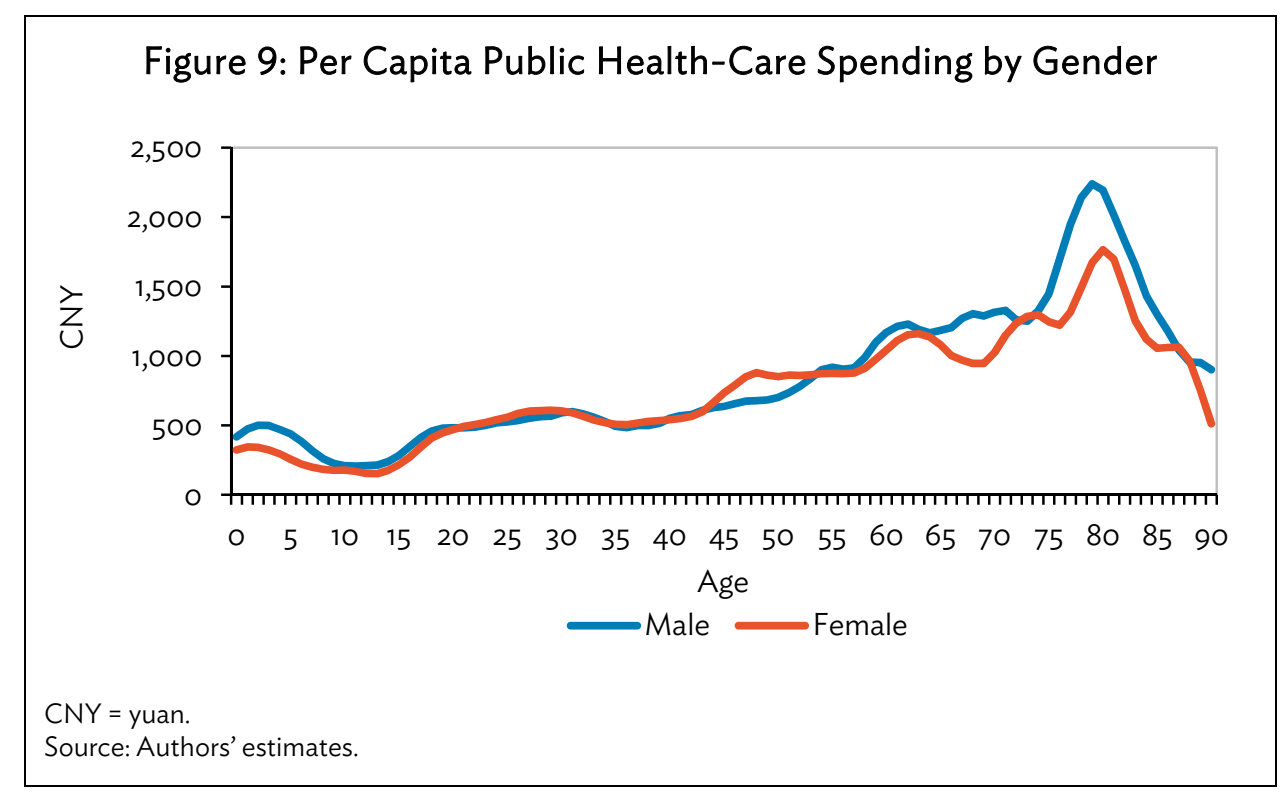

Aggregate public health-care consumption for men was $8 \%$ higher than that for women. As shown in Figure 10, the escalating number of live male births per 100 female live births since the mid1980s, which reached 118.1 in 2010, exacerbated the differences in aggregate spending between males and females younger than the age of 13. In contrast to higher per capita public health-care spending for older men, the aggregate expenditure was roughly gender neutral for older people as female life expectancy is longer than male life expectancy. 


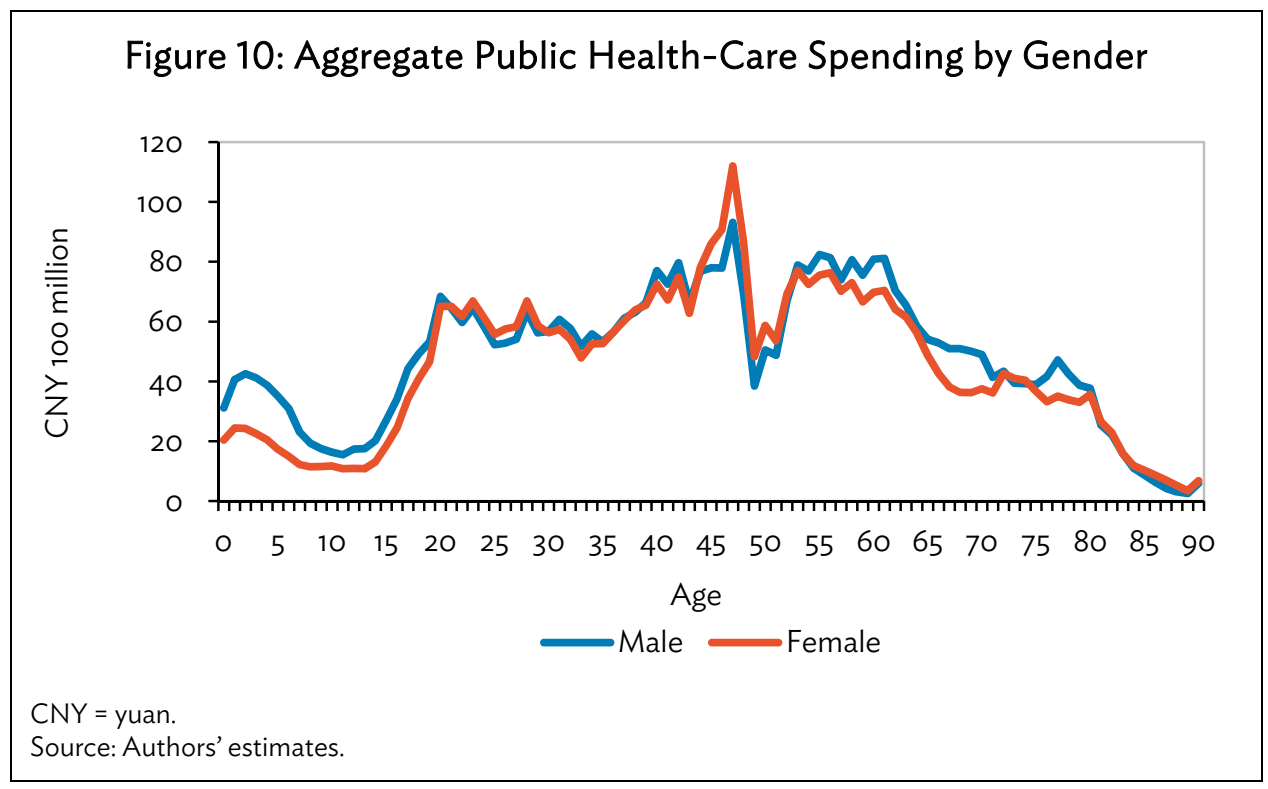

\section{Pensions}

Figure 11 shows gender differentials in per capita pension benefits. Pension benefits for women in their late 50s were higher than those for men as urban female workers are entitled to pensions at the age of 50 or 55 , while urban male workers have to wait until the age of 60 , but benefits for males increase substantially with age. For instance, the value of annual pension benefits was CNY2,652 for men aged 60 but more than double for men aged 80 . Compared with men, per capita pension benefits for women increased much more slowly with age and decreased drastically after age 80 because of lower coverage rates and lower benefits per beneficiary. The 2010 census data showed that only 20\% of women aged 80 cited public pensions as their major source of income in contrast to nearly $40 \%$ of men that age. Hence, currently, public support programs still play a minor role in elderly livelihoods, especially among very elderly females.

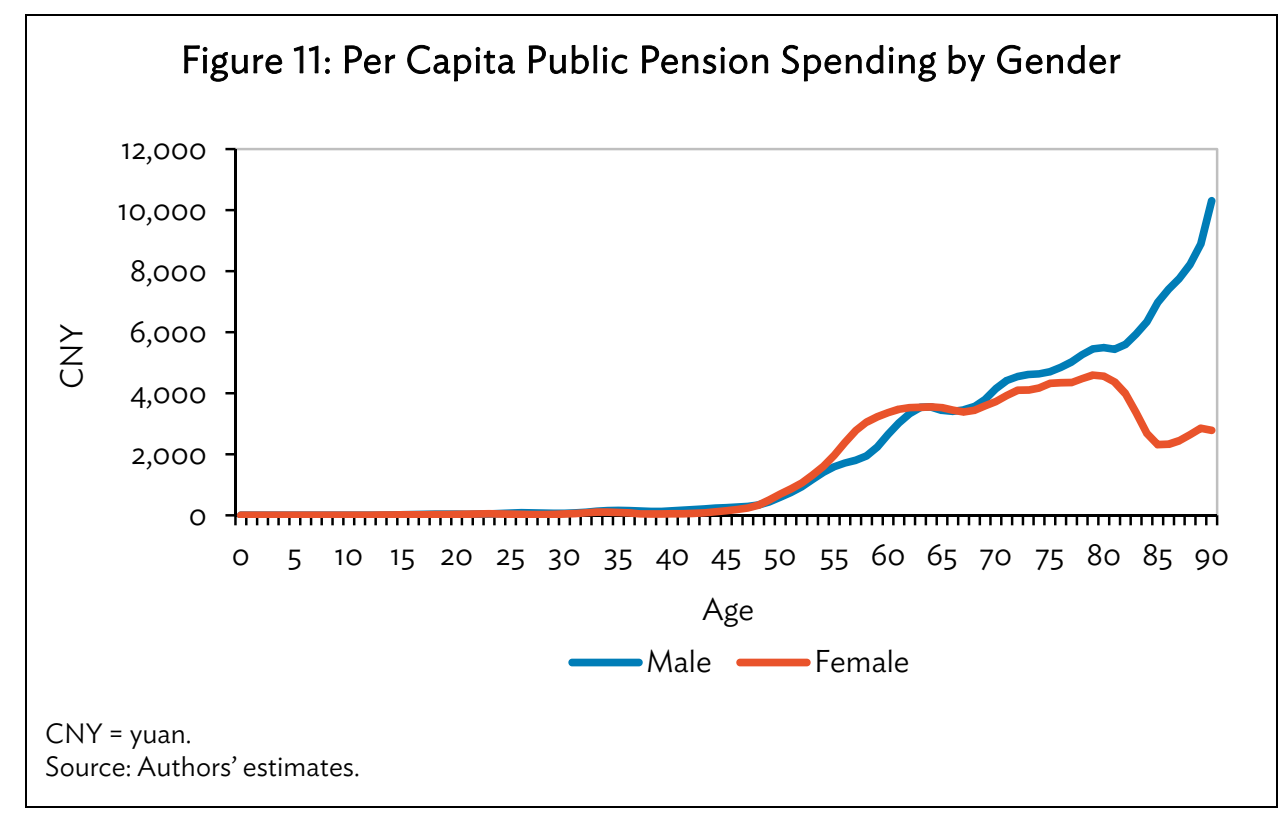


In terms of aggregate pension benefits, the age profiles for men and women both peaked around age 60 and then declined (Figure 12). A noticeable difference from per capita pension benefits is that aggregate pension spending was almost equal for men and women older than 60 as women have lower per capita pension benefits but a better possibility of surviving into older age.

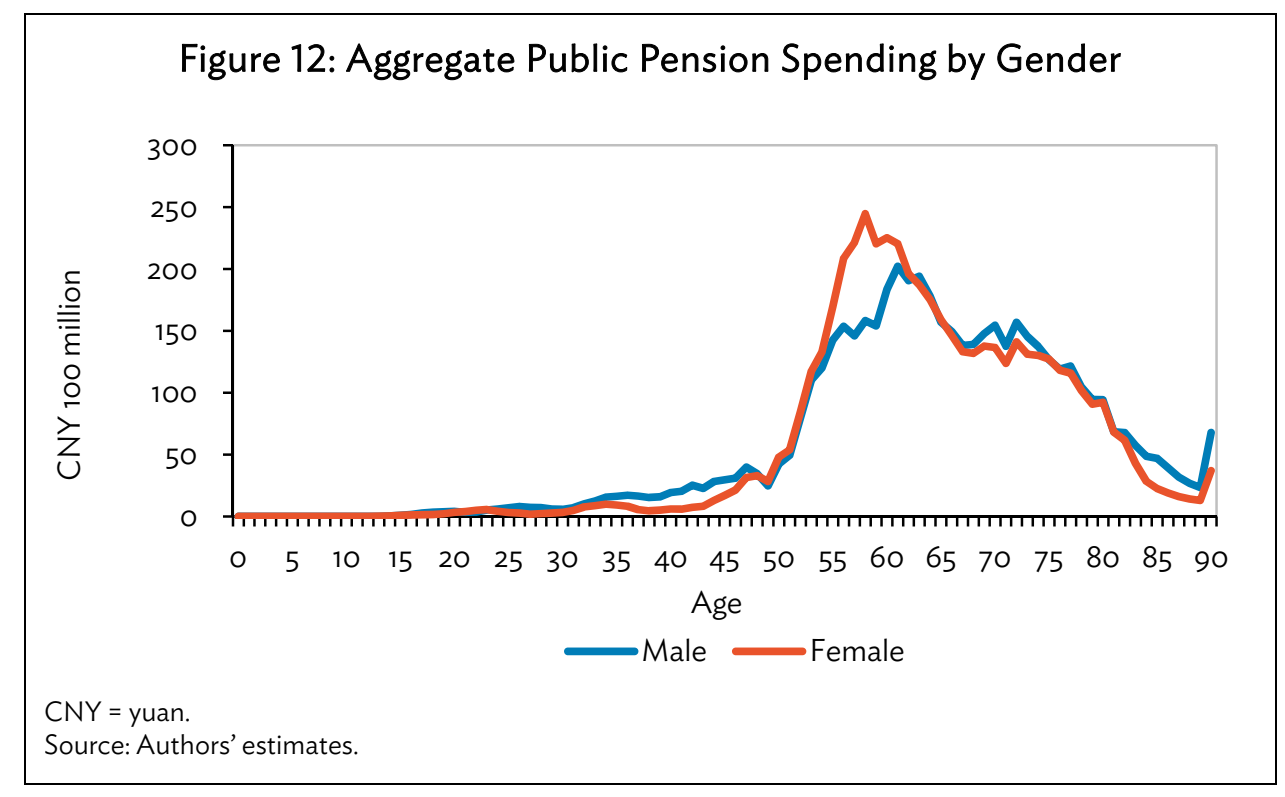

\section{BENEFIT INCIDENCE OF PUBLIC SPENDING BY PER CAPITA HOUSEHOLD INCOME}

This section estimates the benefit incidence of government spending across income groups to examine whether public transfers attenuate income inequalities. The CFPS sample was divided into four income quartiles by per capita household income in the last year.

\section{A. Education}

As shown in Figure 13, the age pattern of per capita public education spending was similar for the lower income quartiles. Their peak education consumption occurred at age 15, i.e., the age for enrolling in senior high school. There are, however, several distinctive differences among the lower three quartiles and the top quartile. First of all, the top quartile received more public education resources for children under the age of 5, indicating that children from wealthier families were more likely to be enrolled in kindergarten. Pre-primary education has not yet been included in compulsory education and thus charges higher tuition fees.

Second, children in the top quartile have a much higher probability of entering college compared with the other income groups. Under the earlier central planning regime, higher education was heavily subsidized ( $\mathrm{Li}$ et al. 2013). College students were not only exempted from tuition fees but also received monthly allowances. With the expansion of higher education, the government gradually reduced the subsidies. From 1995 to 2004, college tuition fees increased sharply from CNY800 per person per year to CNY5,000 on average (Yang 2006). Education expenditures ranked first in total household expenditures in the Tenth Five-Year Plan. The ever increasing tuition fees have intensified the financial constraints of lower income families, and some poor students might even give up the 
opportunity to enter college. Students from wealthier families therefore benefit more from the recent expansion of higher education (Li 2007).

Third, adults older than 25 in the top quartile received public education funds indicating that they were pursuing post-graduate education or adult education, but this was not true in lower income quartiles where funding covered children and adults younger than 25 only. The resulting differences in educational attainment in turn become a source of income inequality.

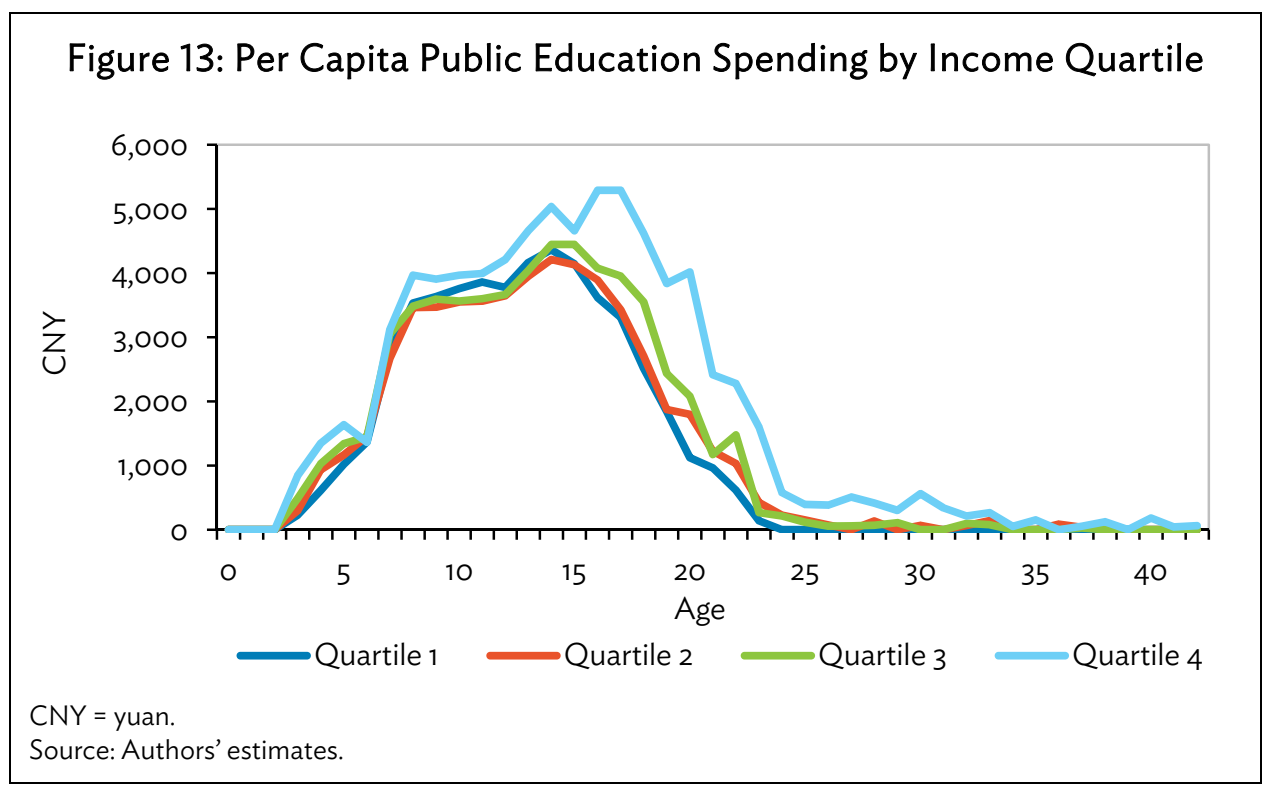

The ratio of public education spending in the top three quartiles to that in the bottom quartile is presented in Figure 14. Public spending on education appears to be neutral with respect to income as it was almost the same for all quartiles. This finding is misleading, however, as the share of school-age children in the poorer quartiles is much greater. This difference in population distribution explains why children aged 6-16 from wealthier families received less public education funding as shown in Figure 15. The concentration of children in lower income groups has several complementary reasons. First, per capita income in our analyses was estimated by dividing household income by the number of household members. Thus, households with more dependent children are more likely to be in lower income quartiles. Second, poorer families tend to have higher fertility, especially as family planning policies differ by region and ethnicity in the PRC. As mentioned previously, rural couples in a majority of provinces are allowed to have a second child if the first birth is female, and minority couples are allowed to have two children in any case. Urban couples, on the other hand, follow the strict one-child per couple rule. Over the age of 20 , young people in higher income quartiles consume more education resources in total due both to the larger share of young people among higher income groups and higher per capita public education consumption. 


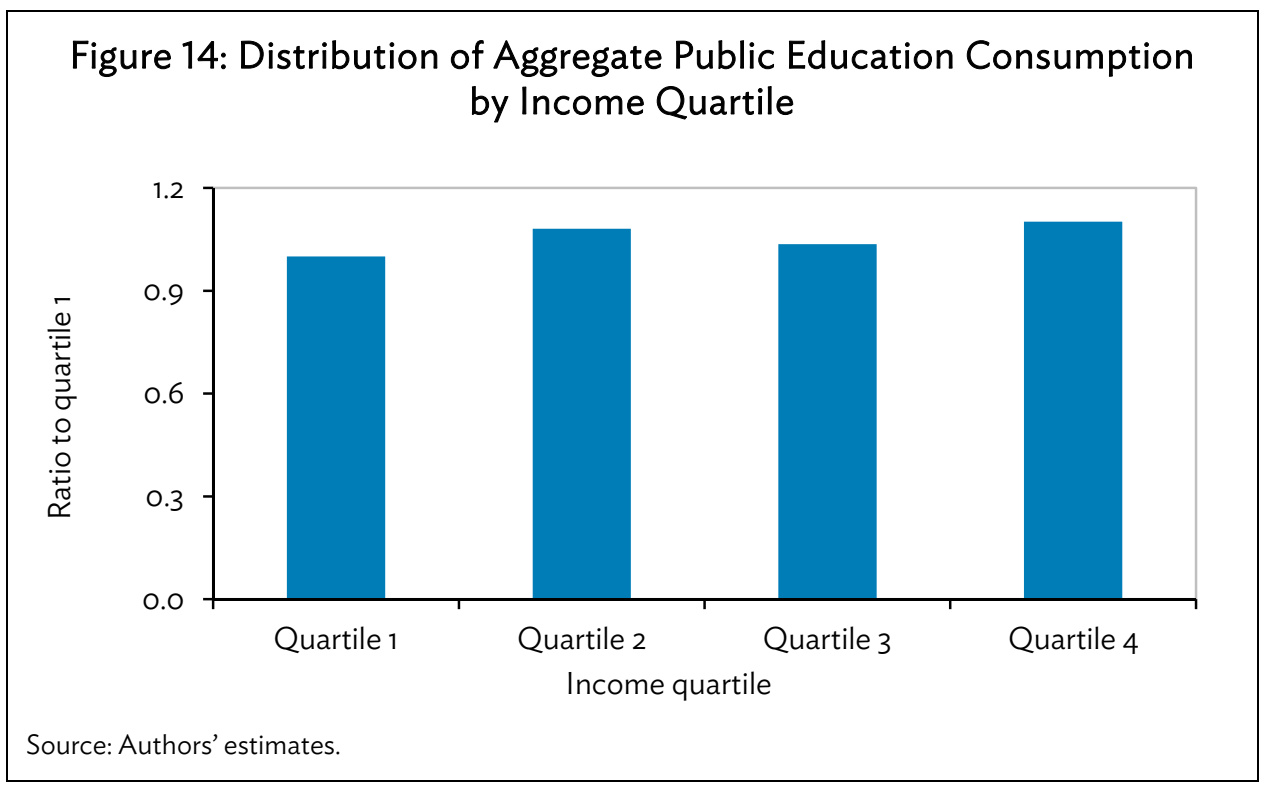

Figure 15: Aggregate Public Education Spending by Income Quartile

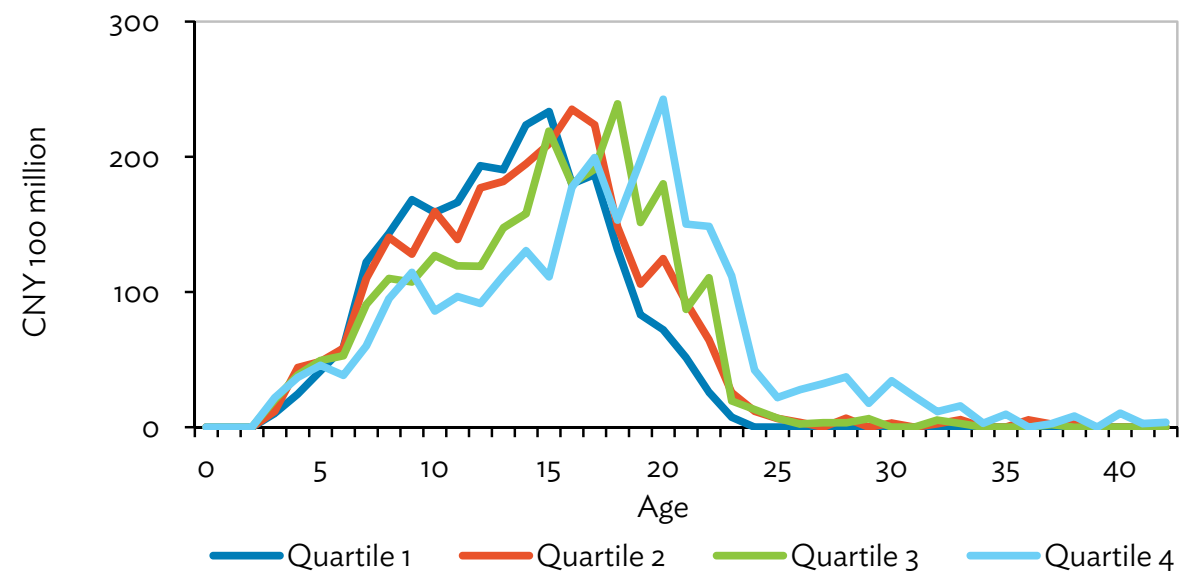

Source: Authors' estimates.

\section{B. Health Care}

Figure 16 conveys two messages. First, public health-care consumption is equally distributed across income groups under the age of 60 . Though higher income groups might be covered by more generous public health insurance, they may also be in better health and thus utilize fewer public resources. Second, per capita spending is targeted to the wealthier groups and is highly skewed in favor of the top quartile over the age of 60, which is the opposite of the pattern in Brazil and Chile (Turra, Holz, and Cotlear 2011). In both those countries, the poor make more intensive use of public health-care services than the rich at all ages because the rich are inclined to use private services. African countries in which public health facilities dominate and private institutions are generally poorly developed show a pattern similar to that of the PRC (Castro-Leal et al.1999). 
Three principal factors affect the use of public health services by the elderly poor: health insurance, income, and access. First, enrollment in health insurance has significantly improved access to health care for older people (Cheng et al. 2013) as they are more susceptible to health problems (Levy and Meltzer 2008) and have more elastic demand for health care (Ringel et al. 2002) than young people. The health insurance status of the elderly is linked to previous employment in urban areas. The top quartile always served in formal sectors prior to retirement and is thus covered by generous health insurance benefits, and more inclined to seek public health care.

Second, health care is a normal good which means that use will increase as income increases. In rural areas, for example, enrollment in the New Rural Cooperative Medical Insurance program significantly increased inpatient service utilization among high-income groups but had no impact on low-income groups because low reimbursement rates and high out-of-pocket medical expenses discouraged poor people from going to hospitals.

Third, poor families often live far away from quality public health institutions and thus face long journeys and high opportunity costs to obtain health care (Castro-Leal et al. 1999). Travel constraints are especially serious for older people.

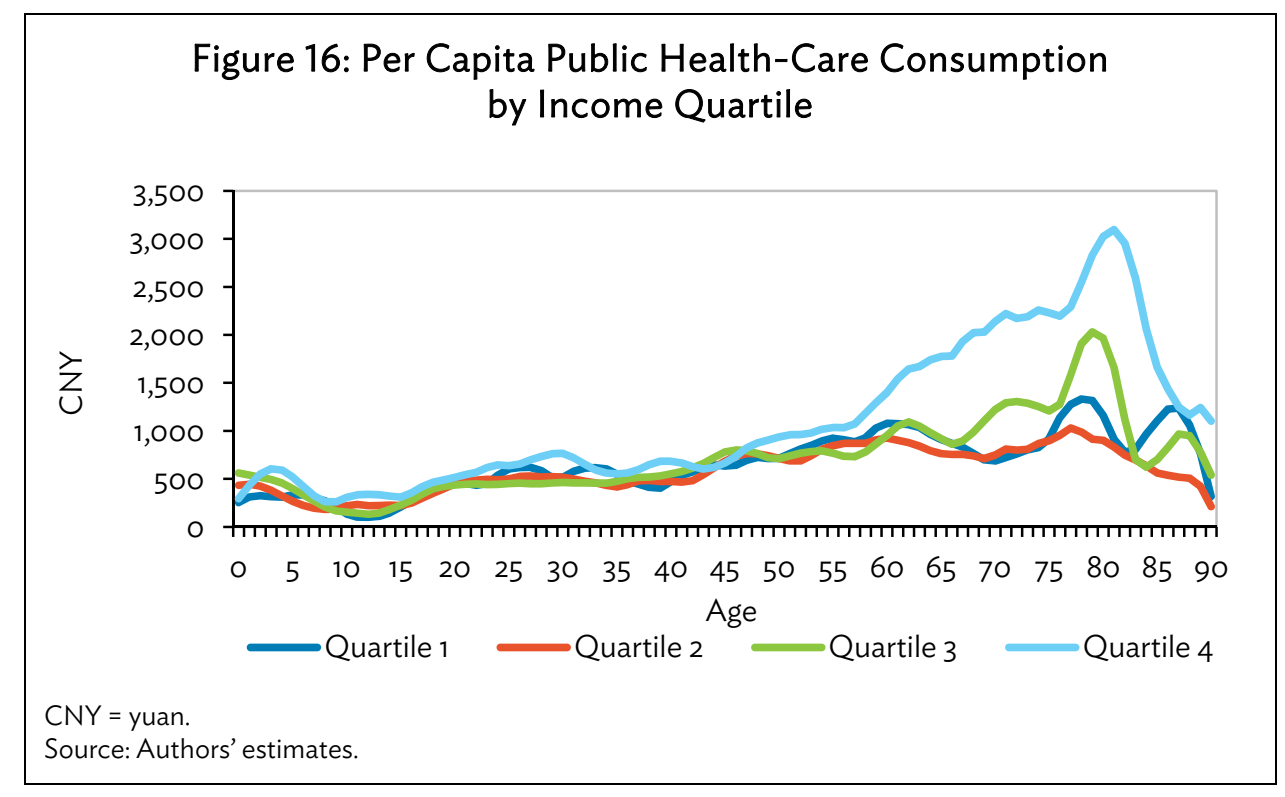

Figure 17 presents the incidence of aggregate public health-care consumption by income quartile. Consumption is equally distributed among the three lower income quartiles, but the transfer to the top quartile is about $60 \%$ higher than the other three. Figure 18 shows the incidence of aggregate health-care spending by age and by income group. Consumption of people in their $20 \mathrm{~s}$ in the top quartile is much higher than that of the other quartiles mainly because there is a concentration of young people in the richest group. In addition, public health spending on the elderly in the top income quartile ranks first, followed by spending on the bottom quartile. This pattern is partly due to the high fraction of older people in the richest and poorest groups. In Brazil and Chile, however, the elderly are more concentrated in the top income groups due to high life-cycle savings and the wide coverage of the pension system. 

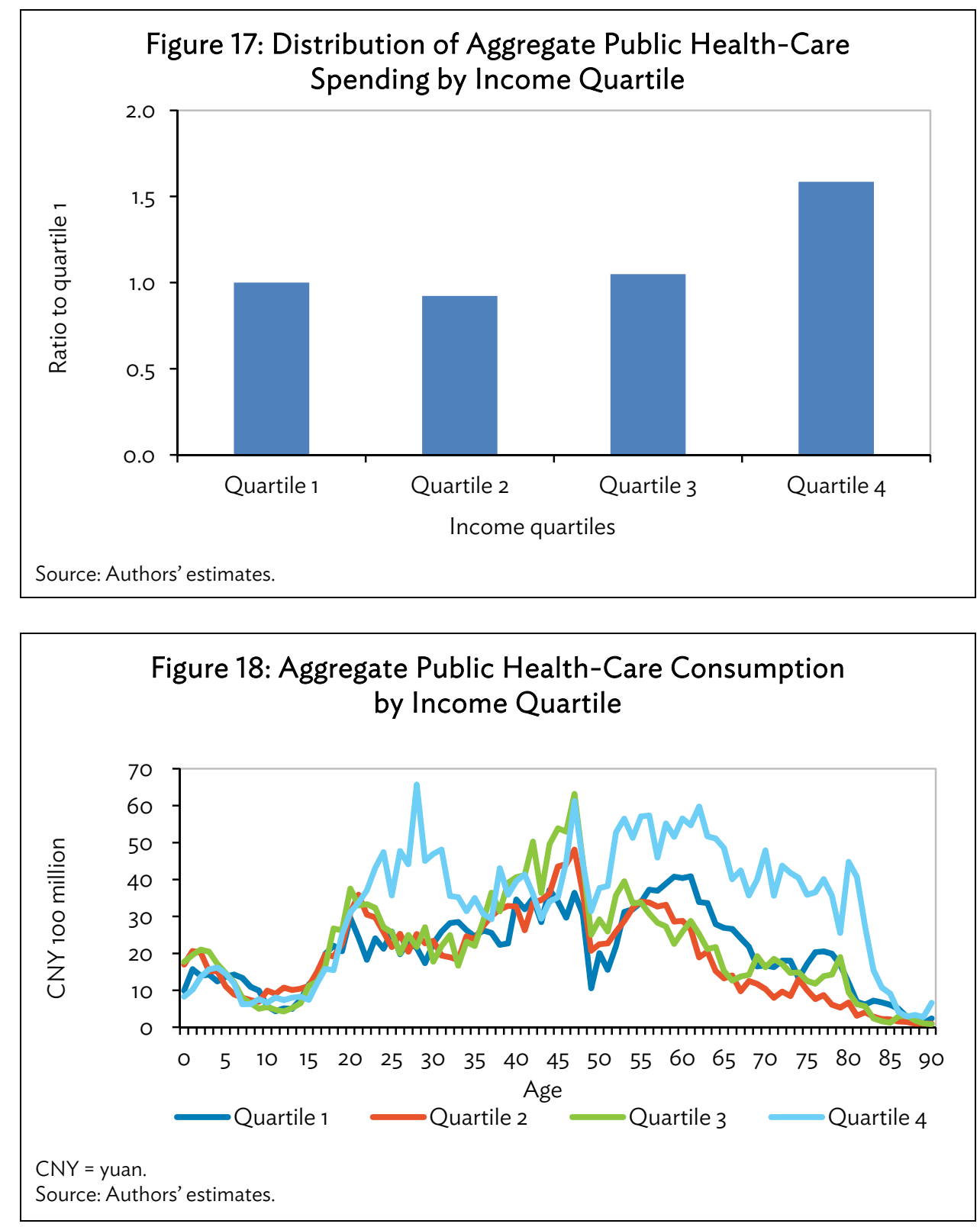

\section{Pensions}

As shown in Figure 19, per capita public pension benefits were strongly regressive, with older people at the top of the income distribution enjoying much greater benefits. The concentration of public transfers in pension benefits in the top quartile is particularly striking compared with public education and health care. For instance, people aged 75 in the top quartile received a pension of CNY11,793 on

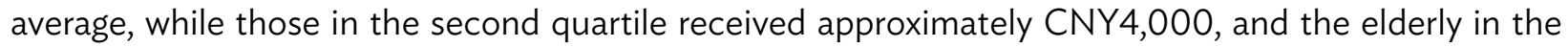
bottom quartile received less than CNY250. Because the pension system in the PRC is a combination of pay-as-you-go and a funded system, the highest paid workers made greater contributions during their working lives and are thus entitled to bigger pensions. On the other hand, as shown in Figure 5, the vast majority of pension benefits were received by urban residents, and the average per capita income 
of urban residents was more than 3 times that of rural residents in 2009. ${ }^{5}$ Therefore, the top income quartile was predominately from urban areas and also enjoyed greater pension benefits.

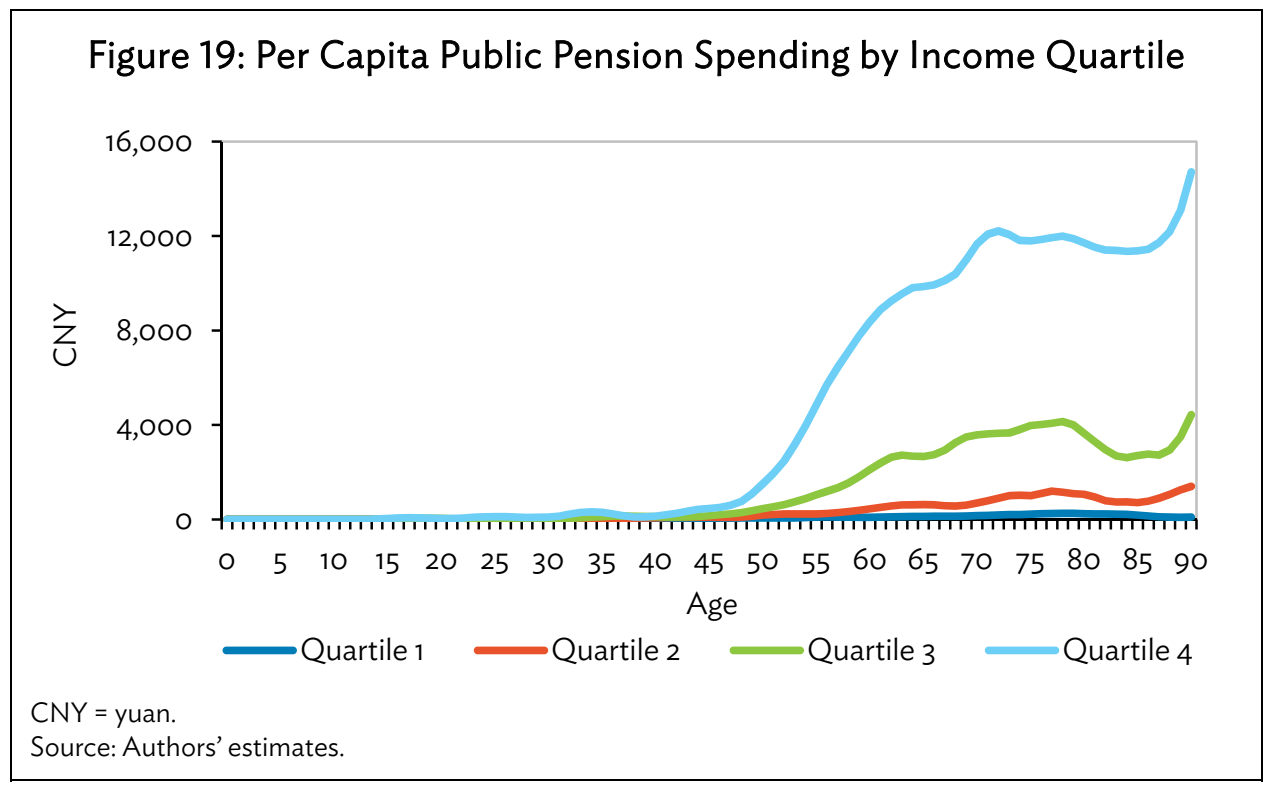

Figure 20 indicates a huge inequality in aggregate pension benefits. Aggregate benefits delivered to the top quartile were 55 times those delivered to the bottom quartile; hence, pension benefits did not favor the poor but rather increasingly rewarded the rich. Gao, Evans, and Garfinkel (2012) compared the distribution of pension benefits in the PRC and Viet Nam, and found that the system in the PRC was much more regressive. As shown in Figure 21, the age profiles of aggregate pension spending show an inverse $U$-shape for each income group, with higher income quartiles peaking at a much higher level.

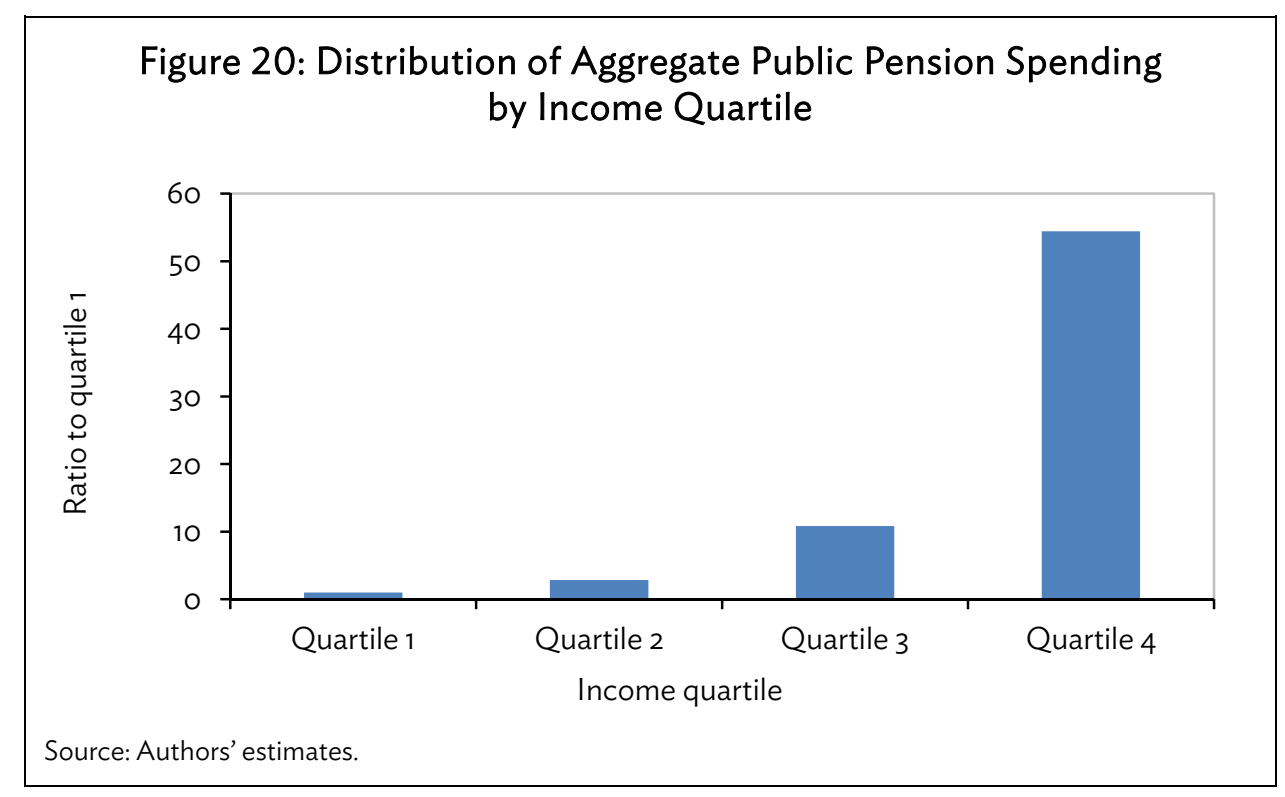

5 In 2009, the average income per capita in urban areas was CNY17,174.7 and was only CNY5,153.2 in rural areas (He 2013). 
Figure 21: Aggregate Public Pension Spending by Income Quartile

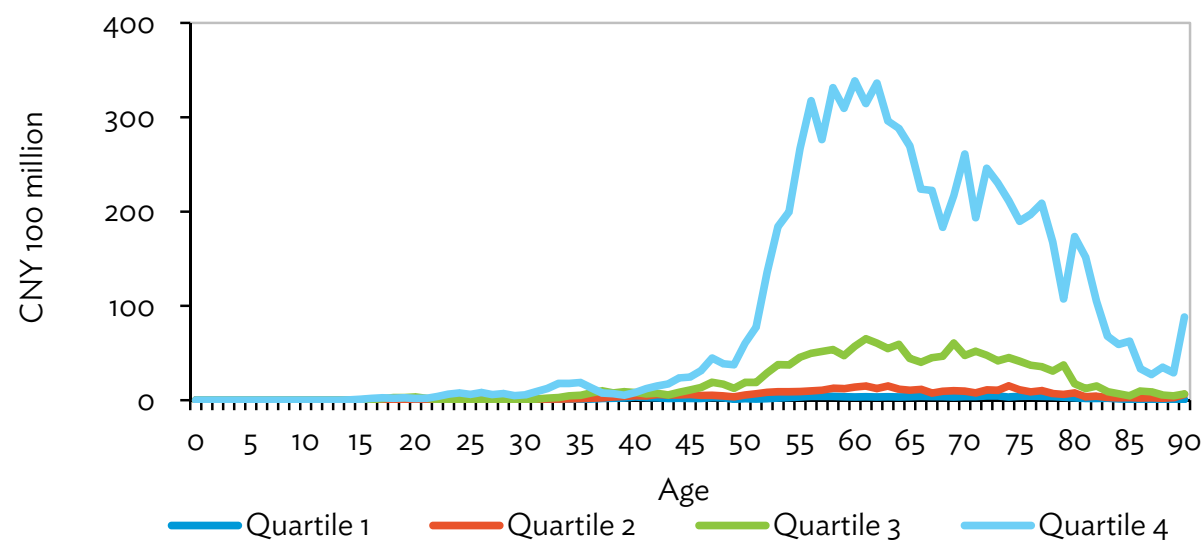

CNY = yuan

Source: Authors' estimates.

\section{BENEFIT INCIDENCE OF TOTAL PUBLIC TRANSFERS}

This section examines whether total public transfers (education, health care, and pensions) are targeted to disadvantaged groups and which generations benefit more from them.

\section{A. Residence}

Figure 22 shows the distribution of per capita total public transfers by age and by residence. Transfers peaked in teenage years in both urban and rural areas at around CNY4,000, and were nearly equal in urban and rural areas before middle age due to equally distributed education and health-care spending. The urban-rural difference in per capita public spending gets increasingly larger after age 45 as urban dwellers receive much higher pension benefits and use public health services more intensively.

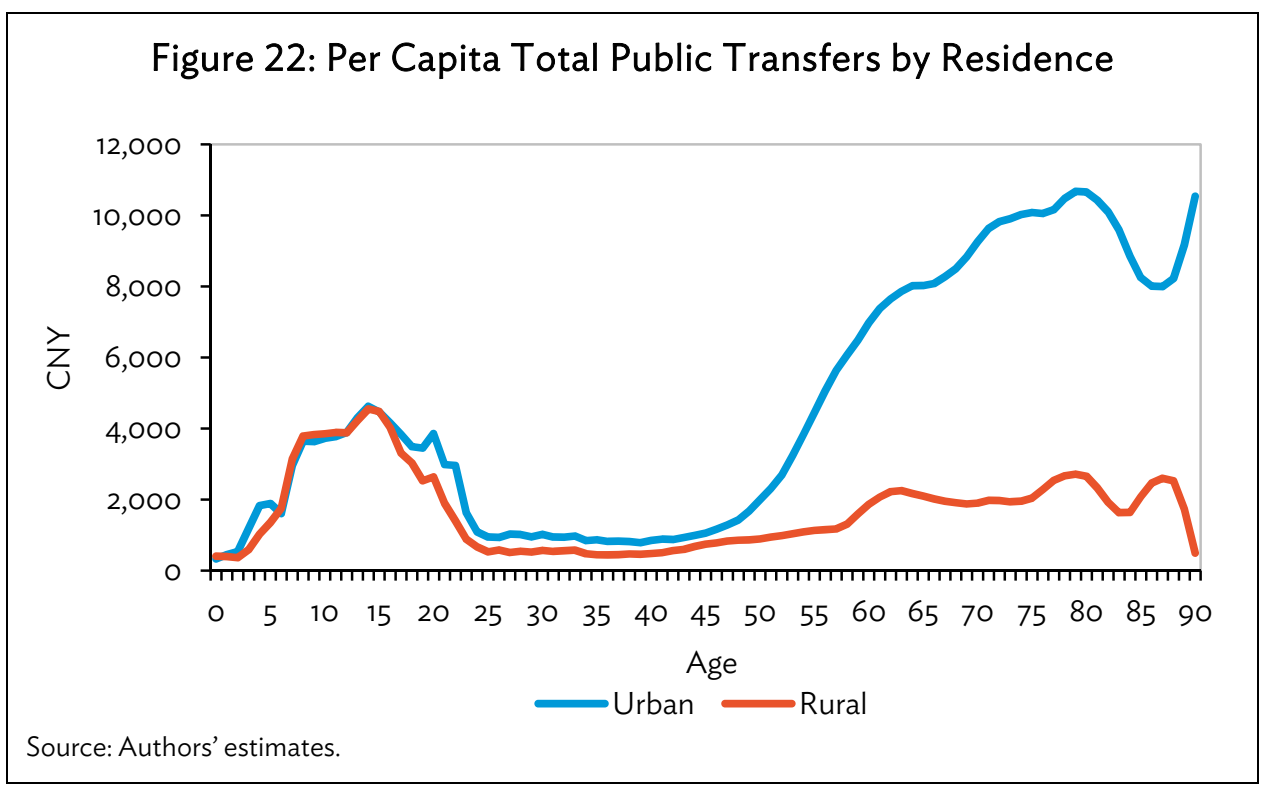


The tilt in public transfers toward the elderly was pronounced in urban areas. Public spending on them averaged more than CNY9,000 per person above the age of 65 , while public spending on children was only CNY2,891 per child under the age of 19 on average. ${ }^{6}$ In contrast, public spending in rural areas was more targeted to children as rural health insurance and the pension system provide limited support for the elderly.

As shown in Figure 23, public spending on children accounted for only $23 \%$ of total spending in urban areas, while the share amounted to $47 \%$ in rural areas partially due to the higher proportion of children in the countryside. Aggregate public spending on people over the age of 65 strongly favored urban residents even though the elderly population in rural areas was larger. In absolute terms, aggregate spending on urban elderly is 3.5 times the spending on rural elderly.

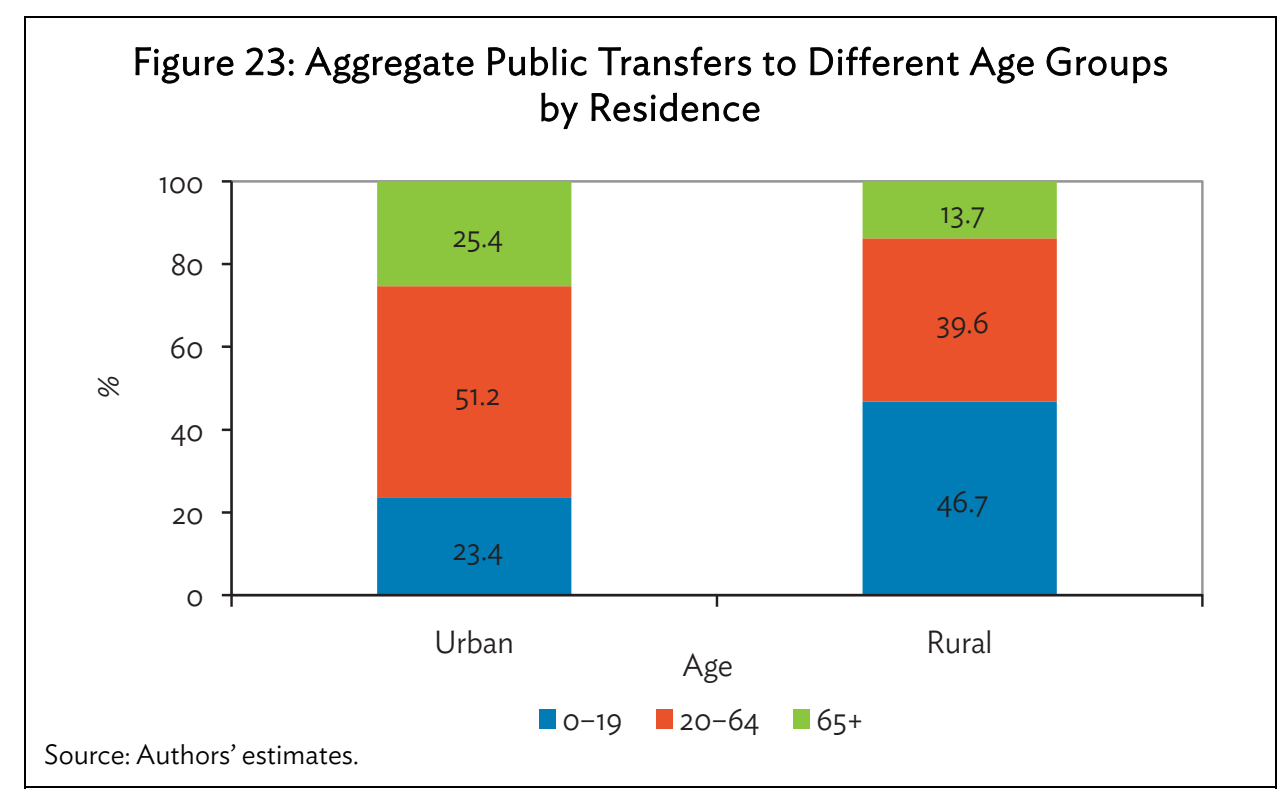

\section{B. Gender}

As shown in Figure 24, per capita profiles of total public transfers coincide for males and females under the age of 65 , indicating they equally take advantage of public education and health-care resources. There is, however, a tilt toward men over the age of 65-especially over the age of 80-due to greater pension benefits for men. The government spent nearly CNY7,000 per male 65 years and older, which was nearly $50 \%$ higher than the CNY4,800 per capita for females.

6 We define the population under 19 years of age as children for two reasons. First, the enrollment rate in senior high school reached $82 \%$ in 2010, indicating most students younger than 19 received public education transfers. Second, Isaacs (2009) also adopted this definition in comparing public spending on children and the elderly in the United States. 


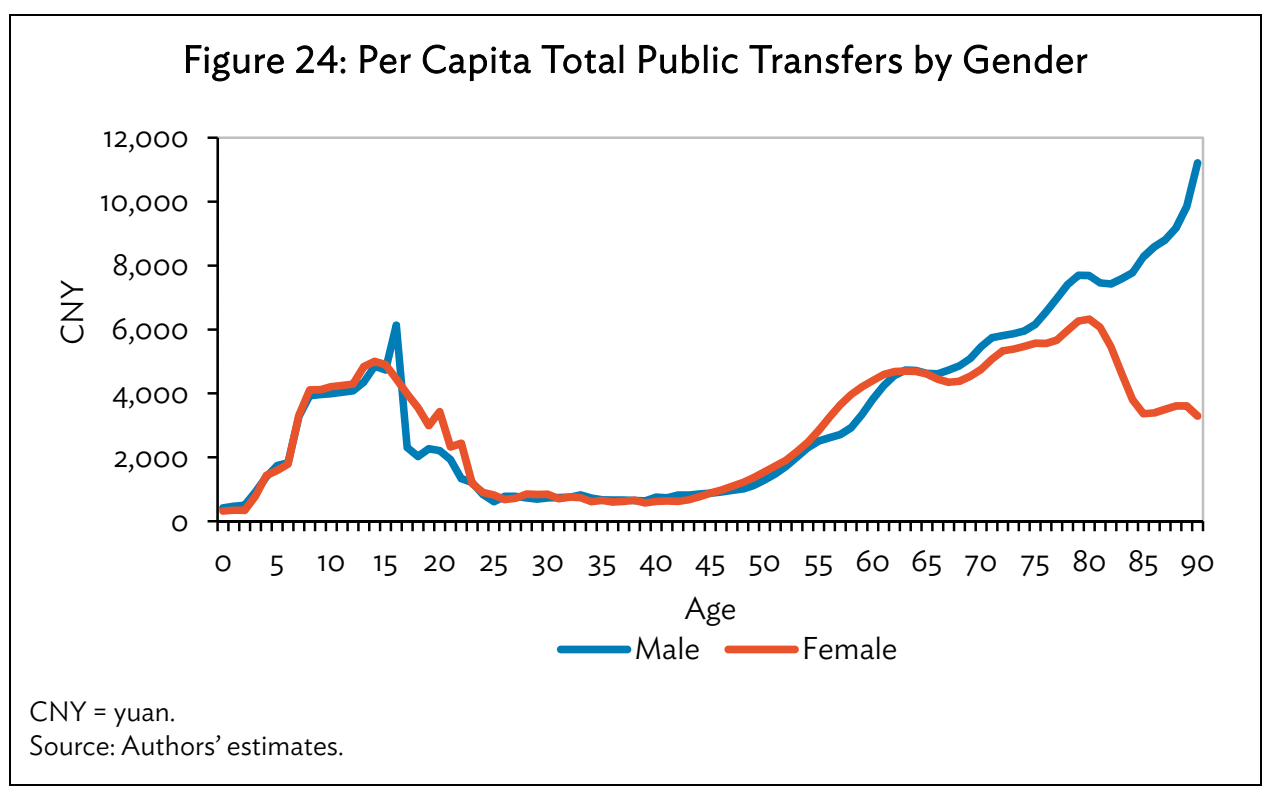

The older generations gained more from public spending than the younger generations did. Despite the strong interest most people in the PRC have in the well-being of children, per capita public spending on children was relatively modest, while the amount spent on health care and pensions for the elderly was greater. Note that the age bias was much greater for men than for women.

As shown in Figure 25, male children accounted for $34 \%$ of total public spending and the male elderly accounted for $23 \%$. The distribution of public spending to different age groups among the female population was similar, with a greater share spent on working-age people.

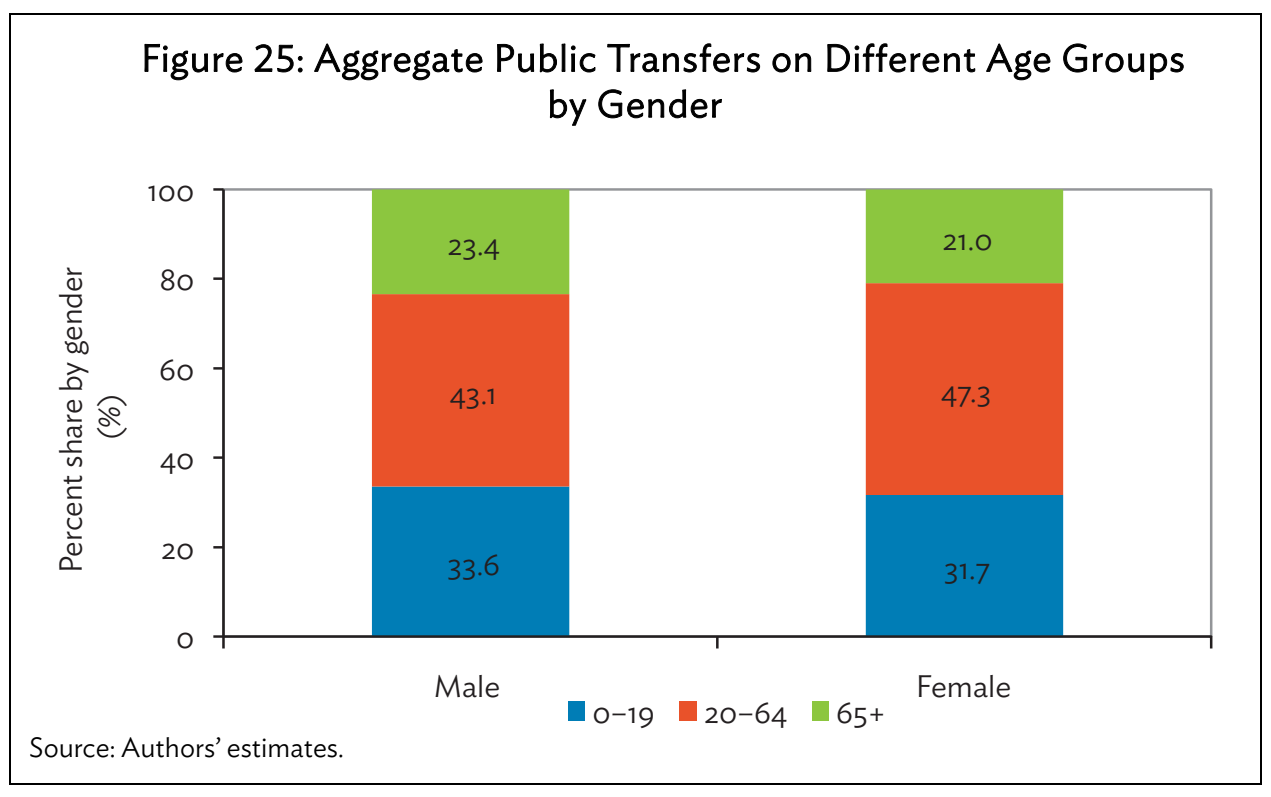




\section{Income Quartiles}

As presented in Figure 26, per capita public spending was equally distributed across income groups among the young and middle-aged but was highly regressive over age 50 . For the bottom quartile, public spending per child amounted to CNY2,689, which was more than twice the public spending per elderly person of CNY1,107. On the contrary, in the top quartile, public spending per elderly person was almost three times greater than public spending per child. This suggests that among higher income groups, the public sector is responsible for the sustenance of the elderly, and families remain responsible for child-rearing.

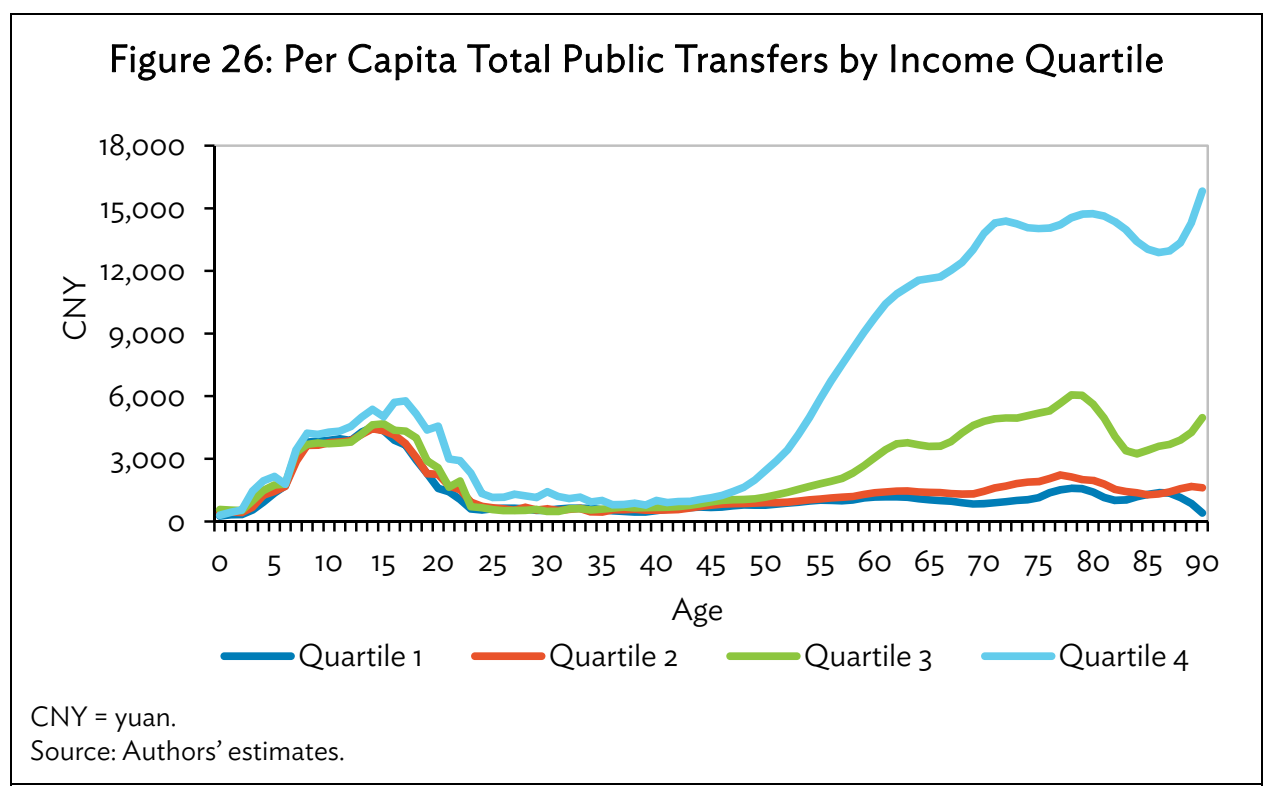

The share of public spending devoted to the elderly was less than $20 \%$ in the second and third quartiles. In contrast, spending on the elderly in the top quartile was 34\% due both to the high proportion of older people and to high levels of per capita spending (Figure 27).

Figure 27: Aggregate Public Transfers on Different Age Groups by Income Quartile

Source: Authors' estimates. 


\section{Incidence of Total Public Transfers}

Figure 28 presents the benefit incidence of public spending across generations in the whole population. Per capita public spending averaged CNY5,619 on people 65 years and older compared with only CNY2,841 on children under the age of 19 . This suggests that public transfers favored the elderly by a factor of 1.98 to 1 . A bias toward the elderly was observed not only in other developing countries such as Brazil and Chile (Turra, Holz, and Cotlear 2011) but also in developed countries. Based on the estimates by Isaacs (2009), per capita public spending on the elderly was 2.4 times the amount on children in the United States (US) in 2004 due to heavy government investment in Social Security and in Medicare.

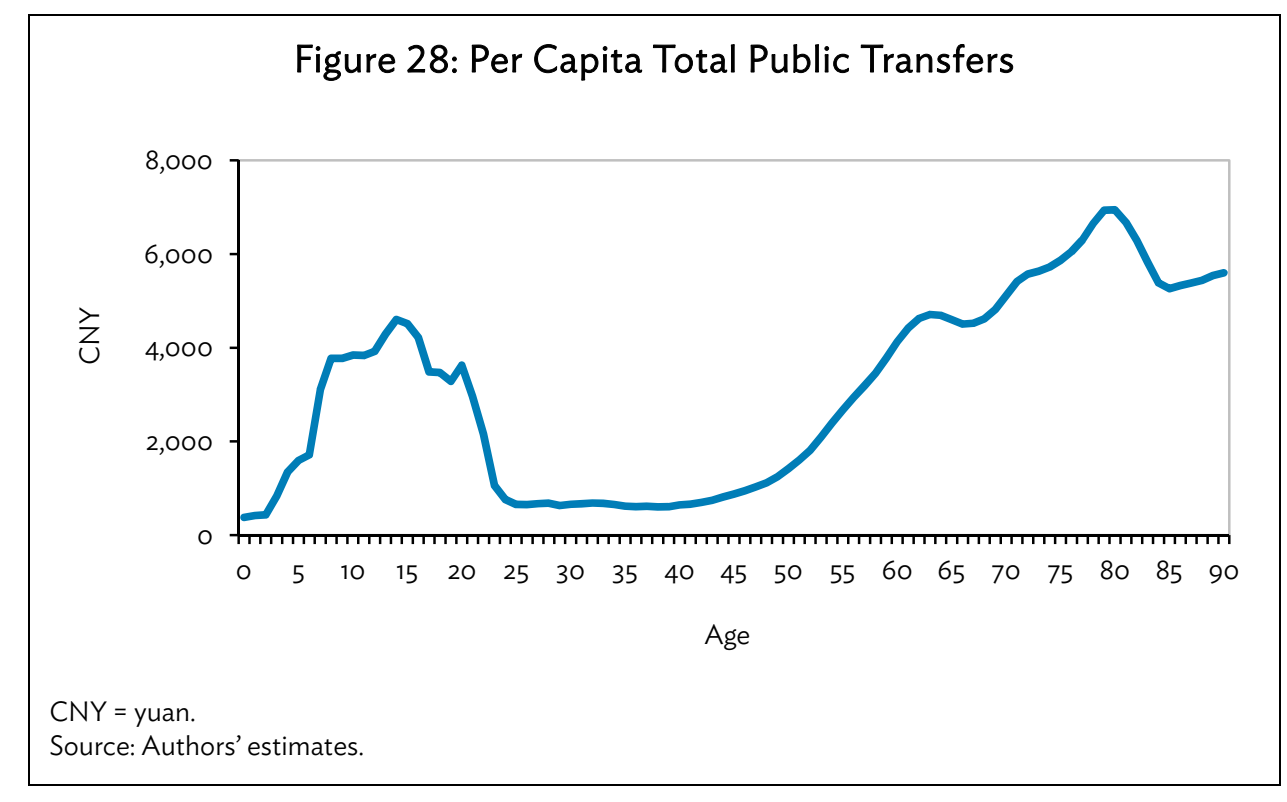

According to estimates, public spending in the PRC on children under the age of 19 totaled CNY931 billion, which was 32\% of total public spending. As a share of the total economy, 3\% of GDP was spent on public support for children in 2009, while the share amounted to 6\% in the US in 2004 (Isaacs 2009). In comparison, public spending on people over the age of 64 totaled CNY646.5 billion and accounted for $22 \%$ of total public transfers. The share of public spending on the elderly was thus $2 \%$ of GDP in contrast to $7 \%$ in the US in 2004 (Isaacs 2009). These comparisons suggest that public transfers played a less important role in supporting dependent children and elderly people in the PRC than in the US, though the tax structure in the US is different from that in the PRC.

\section{CONCLUSION}

Utilizing the National Transfer Accounts (NTA) framework, we systematically analyzed the benefit incidence of public transfers across generations and across socioeconomic groups in the PRC in 2009. Education and health care are basic services essential to combating poverty and are often subsidized with public funds to help achieve that goal. Public education spending was equally distributed by region, gender, and income group at the primary and secondary levels but favored urban residents, females, and the rich at the tertiary level as they have much better chances of going to college. The public health-care program equally benefited people from different socioeconomic groups among the young and middle-aged. However, there was a tilt toward urban dwellers, males, and higher income 
groups at older ages due to higher utilization rates and more generous reimbursements. Pensions are important public cash transfers and are expected to provide livelihood support for the elderly. Our results show that pension benefits strongly favored higher income groups as rural residents, females, and lower income groups received much less in the way of benefits. For instance, the top quartile received almost $80 \%$ of public pension funding in 2009 in contrast to only $2 \%$ for the bottom quartile. The regressive nature of public pension spending mainly arises from the fragmented pension system in the PRC.

Our results also indicate that public transfers were unevenly distributed across generations. Total public spending per person aged 65 and older was twice the spending per child aged 19 or younger. Though public education spending was almost equivalent to public pension spending in the NTA in 2009, the elderly consumed more public health resources than teenagers, so total public transfers significantly favored the elderly. Generational imbalances in benefit incidence are closely related to population aging which is occurring at an unprecedented pace. As shown in the 2010 census, the population aged 60 and older totaled over 178 million, accounting for $13 \%$ of the entire population, which was 3 percentage points higher compared with the 2000 census. The United Nations projection under the medium fertility variant scenario shows that the population aged 60 and older in the PRC will increase to 340 million by 2030, accounting for $24 \%$ of the total population, and to increase to 440 million by 2050 , which represents $34 \%$ of the total population. (UN 2011) The expansion of the elderly population combined with high levels of spending on the elderly will exert heavy pressure on the government budget in the coming years.

Distributions of public transfers across generations are also connected with distributions of public transfers by socioeconomic groups. For instance, per capita public spending is greater on children than on the elderly in rural areas and among lower income groups, while public spending is evidently targeted to elderly persons and to high-income groups in urban areas. Per capita public transfers were equally distributed across socioeconomic groups among the young and middle-aged. However, they were highly regressive at older ages favoring urban dwellers, males, and rich people.

Our results have provided important insights into the problems facing the PRC government that is struggling to deliver essential and equitable social services to its citizens. In the next 10 or 20 years, the government should endeavor to improve and strengthen public support systems. Public transfers, including education, health care, and pensions, accounted for 9\% of GDP in 2009, while Social Security, Medicare, and Medicaid combined accounted for almost 9\% of GDP in the US in 2008, without taking into account public education (Isaacs 2009). In addition to increasing government investments, the currently fragmented health insurance system and pension system should move toward a unified system to reduce inequalities in benefit incidence across socioeconomic groups. In the past decade, the PRC government has been dedicated to targeting the poor with programs that extend public health insurance and pensions to the rural population, but regional and socioeconomic disparities are still evident. At present, the elderly living in rural areas and those in low-income groups rely heavily on transfers from their children to cover living expenses and medical care. With declining fertility and frequent migration, the large, strong family network weakens or even collapses. If the disadvantaged elderly are not well targeted by government programs, the level of inequality will be greater.

While we present abundant evidence on the benefit incidence of public transfers, our findings should be interpreted with caution. First, the nature of the data and of the NTA method necessitates making a variety of assumptions in the calculations; the results should be taken as indicative rather than definitive. For instance, as public education spending in urban and rural areas is not available from 
government financial statistics, the estimated urban and rural differentials in the age distribution of public education spending mainly reflect differentials in enrollment rates. Our results might underestimate urban-rural gaps if government spending on rural schools is less than that on urban schools.

Second, due to price differentials by urban and rural residence and across regions, the differences in real values of public spending would be smaller than the differences in nominal values by place of residence. Thus, those in rural areas and in less-developed regions might be better targeted than was done in our estimation.

Third, CFPS data do not indicate whether a child is in public school or private school. We assumed that all children were enrolled in public schools given the dominance of public education in the PRC. For instance, the China Education Yearbook 2009 indicates that the share of public school students to all students was $95 \%$ for primary education, $92 \%$ for middle school education, and almost $80 \%$ for tertiary education in 2009. Children in urban areas or from wealthier families are more likely to attend private schools, which might bias our estimates. Further investigation into this issue is needed.

Fourth, we divided the urban and rural population based on current residence instead of hukou status, i.e., the registered residency status of a particular individual. This division is also adopted in measuring the urbanization level in the country. This suggests that the urban population in our definition includes the floating population, namely rural migrant workers who reside and work in the cities without an urban hukou. The floating population in the PRC was estimated to be over 260 million in 2012, accounting for 37\% of the urban population (National Health and Family Planning Commission 2013). ${ }^{7}$ Our division alleviates some confusion raised by the division of urban hukou and rural hukou. For instance, rural hukou children are likely to attend schools and go to hospitals in cities, thus consuming urban public resources. Furthermore, some indicators, such as pension benefits, are household amounts in CFPS data and need to be split among household members, some of whom may have urban hukou, while others hold rural hukou. In this circumstance, the split among household members cannot present the real distinction between urban and rural hukou populations.

Fifth, we focused on whether disadvantaged groups received more public transfers than wealthier groups. Another important question is how much the poor received compared with what they paid. This is especially important for public pension spending as some pension benefits are earnings (tax) related. For instance, the average labor income of adults aged 30-49 in the top quartile was 7.3 times (CNY48,816) that of the bottom quartile (CNY6,701), which should affect the size of the pension an individual receives. The figures in the Appendix show public pension spending divided by the average labor income of adults aged $30-49$ by residence, by gender, and by income quartiles in 2009. The results still show that public pensions strongly favored urban and high-income groups. However, the previous results changed as the lowest income groups received more pension benefits than the bottom 50\% income percentile. Furthermore, it appears that most women received more pension benefits than their male counterparts compared with their labor income. This result should, however, be interpreted with care as the analysis requires detailed tax payment profiles that are beyond the scope of this paper.

$7 \quad$ The urban population reached 711.8 million in 2012. 


\section{APPENDIX: PER CAPITA PUBLIC PENSION SPENDING NORMALIZED BY LABOR INCOME OF PEOPLE AGED 30-49}
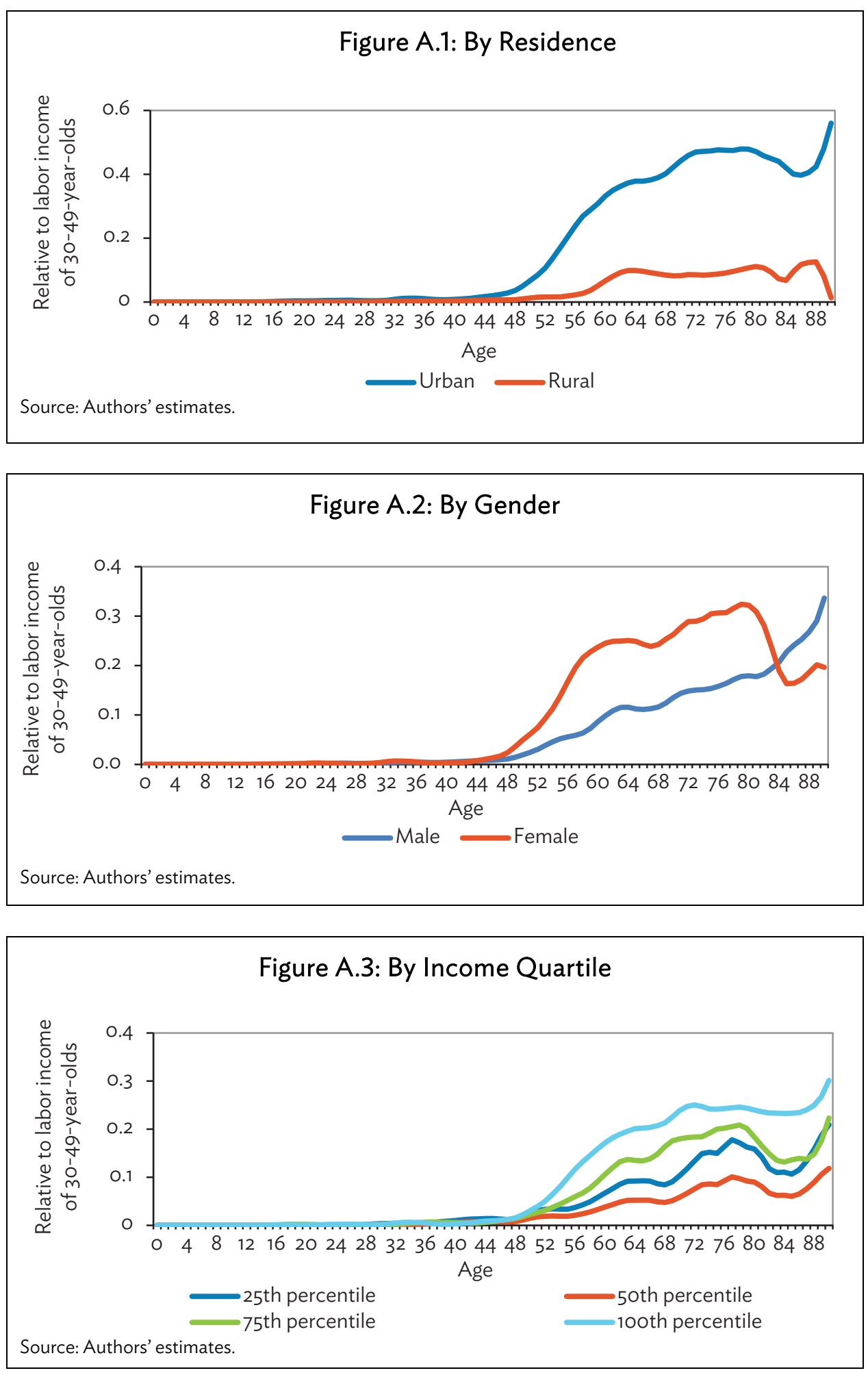


\section{REFERENCES*}

Barber, S. L. and L. Yao. 2010. Health Insurance Systems in China: A Briefing Note. World Health Report Background Paper 37. Geneva: World Health Organization. http://www.who.int/healthsystems/ topics/financing/healthreport/37ChinaB_YFINAL.pdf

Bommier, A., R. Lee, T. Miller, and S. Zuber. 2010. Who Wins and Who Loses? Public Transfer Accounts for US Generations Born 1850 to 2090. NBER Working Paper Series No. 10969. Cambridge, MA: National Bureau of Economic Research (NBER).

Buchmann, C. and T. A. DiPrete. 2006. The Growing Female Advantage in College Completion: The Role of Family Background and Academic Achievement. American Sociological Review. 71 (4). pp. 515-541. http://asr.sagepub.com/content/71/4/515.abstract

Castro-Leal, F., J. Dayton, L. Demery, and K. Mehra. 1999. Public Social Spending in Africa: Do the Poor Benefit? The World Bank Research Observer. 14 (1). pp. 49-72. http://wbro.oxfordjournals.org/ content/14/1/49.abstract

Chen, Weiguang, ed. 2010. China Educational Finance Statistical Yearbook. Beijing: China Statistics Press.

Cheng, L., H. Liu, K. Shen, Y. Zhang, and Y. Zeng. 2013. The Impact of Health Insurance on Health Outcomes and Spending of the Elderly: Evidence from China's New Cooperative Medical Scheme. http://papers.ssrn.com/sol3/papers.cfm?abstract_id=2280202

Gao, Q., M. Evans, and I. Garfinkel. 2012. Social Benefits and Income Inequality in Post-Socialist China and Vietnam. http://umdcipe.org/conferences/policy_exchanges/conf_papers/Papers/gaoevans-garfinkel.pdf

Government of the People's Republic of China, Ministry of Health. 2004. Report on China's Health Care Development. Beijing.

- - , - - - 2012. China Public Health Statistical Yearbook. Beijing: Peking Union Medical College Publishing House.

-_- National Bureau of Statistics. 2010. Sixth National Population Census. Beijing: China Statistics Press.

_-_._-_. 2012. The People's Republic of China Yearbook 2011. Beijing: China Yearbook Press.

- - - National Health and Family Planning Commission. 2009. China Education Yearbook. Beijing: People's Education Press.

_-_, - - 2013. Monitoring Report on China's Rural Migrant Workers. Beijing.

He, J., ed. 2013. China Financial Yearbook. Beijing: Financial Magazine of China. Institute of Social Science Survey. 2010. China Family Panel Studies. Beijing: Peking University.

Isaacs, J. B. 2009. How Much Do We Spend on Children and the Elderly? Washington, DC: Brookings Institution.

* ADB recognizes China as the People's Republic of China. 
Lai, F. 2010. Are Boys Left Behind? The Evolution of the Gender Achievement Gap in Beijing's Middle Schools. Economics of Education Review. 29 (3). pp. 383-399.

Lee, M.-H. 2012. The One-Child Policy and Gender Equality in Education in China: Evidence from Household Data. Journal of Family and Economic Issues. 33 (1). pp. 41-52.

Lee, R. 2003. The Demographic Transition: Three Centuries of Fundamental Change. The Journal of Economic Perspectives. 17 (14). pp. 167-190.

Levy, H. and D. Meltzer. 2008. The Impact of Health Insurance on Health. Annual Review of Public Health. 29. pp. 399-409.

Li, W. 2007. Family Background, Financial Constraints and Higher Education Attendance in China. Economics of Education Review. 26 (6). pp. 724-734.

Li, S., ed. 2013. China Social Statistical Yearbook. Beijing: China Statistics Press.

Li, S., J. Whalley, and C. Xing. 2013. China's Higher Education Expansion and Unemployment of College Graduates. China Economic Review. In Press.

Meerman, J. 1979. Public Expenditures in Malaysia: Who Benefits and Why? New York: Oxford University Press.

People's Daily. 2009. Let's Talk: Focus on Fewer and Fewer Rural Students in Universities (in Chinese). 15 January. http://edu.people.com.cn/GB/1053/8676707.html

Pozen, R. C. 2013. Tackling the Chinese Pension System. Paulson Policy Memorandum. Chicago: The Paulson Institute.

Ringel, J. S., S. D. Hosek, B. A. Vollaard, and S. Mahnovski. 2002. The Elasticity of Demand for Health Care: A Review of the Literature and Its Application to the Military Health System. http://www .rand.org/pubs/monograph_reports/MR1355.html

Selowsky, M. 1979. Who Benefits from Government Expenditure?: A Case Study of Colombia. New York: Oxford University Press.

Sheng, L., ed. 2011. China Statistical Yearbook. Beijing: China Statistics Press.

Strauss, J., H. Hong, X. Lei, L. Li, A. Park, L. Yang, and Y. Zhao. 2012. Health Care and Insurance among the Elderly in China: Evidence from the CHARLS Pilot. http://ihome.ust.hk/ albertpark/ papers/NAS_health.pdf

Turra, C. M., M. Holz, and D. Cotlear. 2011. Who Benefits from Public Transfers? Incidence across Income Groups and across Generations in Brazil and Chile. In D. Cotlear, ed. Population Aging: Is Latin America Ready? Washington, DC: World Bank.

United Nations, Department of Economic and Social Affairs Population Division. 2011. World Population Prospects:The 2010 Revision. New York. 
- - -_-_. 2013. National Transfer Accounts Manual: Measuring and Analysing the Generational Economy. New York.

United Nations Human Settlements Programme (UN-HABITAT). 2008. State of The World's Cities 2010/2011: Bridging the Urban Divide. Nairobi.

van de Walle, D. and K. Nead, eds. 1995. Public Spending and the Poor: Theory and Evidence. Baltimore: Johns Hopkins University Press.

Wu, X. and Z. Zhang. 2010. Changes in Educational Inequality in China, 1990-2005: Evidence from the Population Census Data. In E. Hannum, H. Park, and Y. G. Butler, eds. Globalization, Changing Demographics, and Educational Challenges in East Asia (Research in the Sociology of Education, Volume 17). Bingley, UK: Emerald Group Publishing Limited.

Xinhua News. 2013. China Gini Coefficient at 0.474 in 2012. 18 January. http://news.xinhuanet.com/ english/china/2013-01/18/c_132111927.htm

Xu, Q., C. Zhang, X. Zhou, and Y. Xie. 2012. Comparison in Income Data among CGSS, CHIP, CFPS and CFPS Surveys. http://www.isss.edu.cn/cfps/d/file/wd/jsbg/2010jsbg/a29e71f54de2f5dcd 71c6284e4eed017.pdf

Yan, J., X. Sun, X. Teng, L. Ren, and Y. Sun. 2012. Report on Quality Control of 2010 China Family Panel Studies Survey. http://www.isss.edu.cn/cfps/d/file/wd/jsbg/2010jsbg/bc8d67c159ff99efdde94 5137191b133.pdf

Yang, D. 2006. Transition and Development of China's Education. Beijing: Social Science Academic Press (in Chinese). 


\section{Benefit Incidence of Public Transfers}

Evidence from the People's Republic of China

Employing the National Transfer Account framework, this paper analyzes the benefit incidence of public transfers across generations and socioeconomic groups in the People's Republic of China in 2009. Public transfers as a whole are unevenly distributed across generations, with spending on the elderly twice as much as that on the young. Public education spending is equally distributed at the primary and secondary levels but favors urban residents, females, and higher income groups at the tertiary level. Disparities in public spending on health care are much greater at older ages. Public pension is highly regressive, with rural residents, women, and lower income groups receiving much lower pension benefits.

\section{About the Asian Development Bank}

ADB's vision is an Asia and Pacific region free of poverty. Its mission is to help its developing member countries reduce poverty and improve the quality of life of their people. Despite the region's many successes, it remains home to approximately two-thirds of the world's poor: 1.6 billion people who live on less than $\$ 2$ a day, with 733 million struggling on less than $\$ 1.25$ a day. ADB is committed to reducing poverty through inclusive economic growth, environmentally sustainable growth, and regional integration.

Based in Manila, ADB is owned by 67 members, including 48 from the region. Its main instruments for helping its developing member countries are policy dialogue, loans, equity investments, guarantees, grants, and technical assistance. 